\title{
Transition-metal-catalyzed synthesis of phenols and aryl thiols
}

\author{
Yajun Liu ${ }^{* 1}$, Shasha $\mathrm{Liu}^{1}$ and Yan Xiao ${ }^{* 2}$
}

\author{
Review \\ Address: \\ ${ }^{1}$ College of Life Science and Medicine, Dalian University of \\ Technology, Panjin 124221, China and 2Department of \\ Pharmaceutical Engineering, Shenyang Pharmaceutical University, \\ Shenyang 110016, China \\ Email: \\ Yajun Liu* - vjliu85@dlut.edu.cn; Yan Xiao* - xiaoyan@syphu.edu.cn \\ * Corresponding author \\ Keywords: \\ aryl thiol; C-O bond; C-S bond; phenol; transition metal
}

\author{
Beilstein J. Org. Chem. 2017, 13, 589-611. \\ doi:10.3762/bjoc. 13.58 \\ Received: 17 November 2016 \\ Accepted: 09 March 2017 \\ Published: 23 March 2017 \\ Associate Editor: I. Marek \\ (c) 2017 Liu et al.; licensee Beilstein-Institut. \\ License and terms: see end of document.
}

\begin{abstract}
Phenols and aryl thiols are fundamental building blocks in organic synthesis and final products with interesting biological activities. Over the past decades, substantial progress has been made in transition-metal-catalyzed coupling reactions, which resulted in the emergence of new methods for the synthesis of phenols and aryl thiols. Aryl halides have been extensively studied as substrates for the synthesis of phenols and aryl thiols. In very recent years, $\mathrm{C}-\mathrm{H}$ activation represents a powerful strategy for the construction of functionalized phenols directly from various arenes. However, the synthesis of aryl thiols through $\mathrm{C}-\mathrm{H}$ activation has not been reported. In this review, a brief overview is given of the recent advances in synthetic strategies for both phenols and aryl thiols.
\end{abstract}

\section{Introduction}

Phenols and aryl thiols serve as both important intermediates in organic synthesis and also final products, playing important roles in pharmaceutical molecules, pesticides and polymers in both academia and industry [1-4]. Some classic drugs which employ phenols or aryl thiols as central structural motifs are shown in Figure 1.

In the past decade, the transition-metal-catalyzed Ullmann-type coupling reaction has emerged as an effective method, allowing the synthesis of phenols and aryl thiols from aryl halides through $\mathrm{C}-\mathrm{O}$ and $\mathrm{C}-\mathrm{S}$ bond formation, respectively [5-7]. Very recently, the $\mathrm{C}-\mathrm{H}$ activation has made revolutionary advances in organic synthesis because it allows an access to functionalized products from simple arenes, avoiding their pre-functionalization [8-10]. The synthesis of phenols has greatly benefited from $\mathrm{C}-\mathrm{H}$ activation, but the application in the synthesis of aryl thiols is still yet to be reported.

Both phenols and aryl thiols have similar chemical properties, such as acidity and nucleophilicity, and thus to some extent, the synthetic methods could be developed analogously to each other. In this context, it is valuable to compare their existing synthetic methods for better understanding, so as to inspire organic chemists to invent new methods for the synthesis of 


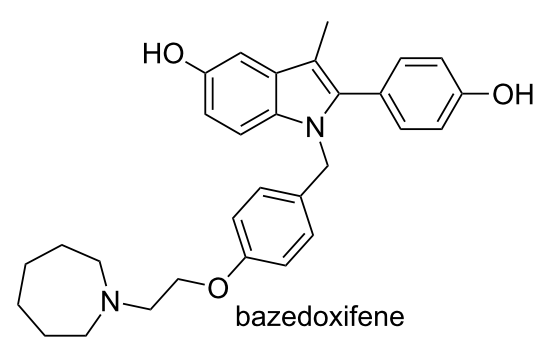<smiles>CCC(=O)C1(c2cccc(O)c2)CCN(C)CC1</smiles>

ketobemidone<smiles>CCC(C)C(=O)c1c(O)cc(O)cc1OC/C=C(\C)CCC=C(C)C</smiles>

olympicin A<smiles>Cn1ccnc1S</smiles>

thiamazole<smiles>Sc1ncnc2nc[nH]c12</smiles>

mercaptopurine

Figure 1: Examples of drugs bearing phenol or aryl thiol as central structural motifs.

these two important classes of compounds. Herein, we review the recent developments on transition-metal-catalyzed syntheses of phenols from aryl halides and arenes, and aryl thiols from aryl halides.

\section{Review}

\section{Transition-metal-catalyzed synthesis of phenols}

In early times, classic methods for the synthesis of phenols included the sulfonation of benzene [11], the Dakin reaction $[12,13]$ and the Sandmeyer-type reaction [14]. These methods are useful for the preparation of various phenols, however, they suffer from several drawbacks such as multistep syntheses, toxic solvents, high temperatures, a narrow substrate scope, low selectivity, and/or low yields.

Inspired by the classic Ullmann reaction $[15,16]$, the development of a transition-metal-catalyzed $\mathrm{C}-\mathrm{O}$ coupling reaction provides various strategies to synthesize $\mathrm{C}-\mathrm{O}$-coupled products including ethers and phenols. On the other hand, the $\mathrm{C}-\mathrm{H}$ hydroxylation, either with heteroatom-containing directing groups or without directing groups, has provided various methods for the synthesis of phenols. Compared with traditional methods, the transition-metal-catalyzed phenol synthesis has several advantages: broad substrate scope, mild reaction conditions, and easy access to starting materials.

\subsection{Aryl halide as substrate}

Compared with other traditional starting materials, such as phenylsulfonic acid, aryl ketone and phenylboronic acid [1720], aryl halides can be considered as simple and economical starting materials for the synthesis of phenols. In the beginning, palladium catalysts have attracted much attention due to their high conversion efficiency, and later copper catalysts, which are cheaper and more stable, have been extensively studied in this field.

1.1.1 Palladium-catalyzed hydroxylation of aryl halides: In 2006, Buchwald and co-workers described the first synthesis of phenols from aryl halides through a palladium-catalyzed reaction [21]. The $\mathrm{C}-\mathrm{O}$ coupling reaction of an aryl halide and potassium hydroxide took place when using $\mathrm{Pd}_{2} \mathrm{dba}_{3}$ as catalyst, biphenylphosphine (L1 or the bulkier $\mathbf{L 2}$ ) as ligand, and 1,4dioxane $/ \mathrm{H}_{2} \mathrm{O}$ as solvent (Scheme 1). Under these conditions, a

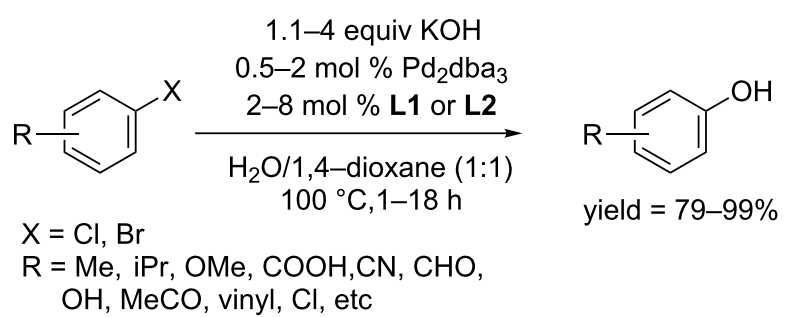<smiles>[Y7]c1cc(C(C)C)cc(C(C)C)c1-c1ccccc1CCC</smiles>

L1<smiles>Cc1c(C)c(C)c(C(C)C)c(-c2c(C(C)C)cc(C(C)C)cc2C(C)C)c1C</smiles>

L2 
wide range of aryl bromides and chlorides could be readily converted to the corresponding phenols in high yields at $100{ }^{\circ} \mathrm{C}$ within 1-18 h. Moreover, sterically hindered ortho-functionalized aryl halides and heteroaryl halides were also converted into the corresponding phenols in excellent yields. Notably, they claimed that hydroxy salt was indispensable for the conversion as a replacement of $\mathrm{KOH}$ with $\mathrm{K}_{3} \mathrm{PO}_{4}$ afforded $99 \%$ yield of diaryl ethers.

Interestingly, the following work developed by the Kwong group in 2007 employed $\mathrm{K}_{3} \mathrm{PO}_{4}$ as the base and succeeded in the hydroxylation of aryl halides [22]. They chose tri-tertbutylphosphine as the ligand in their reaction system and obtained the phenols from aryl halides, suggesting a great influence of the ligand on the reaction performance (Scheme 2). However, their protocol was only suitable for activated halides having an ortho-nitro substituent; lower yields were observed in the case of unactivated aryl halides, such as 2-isopropylbromobenzene and 2,5-dimethylchlorobenzene.

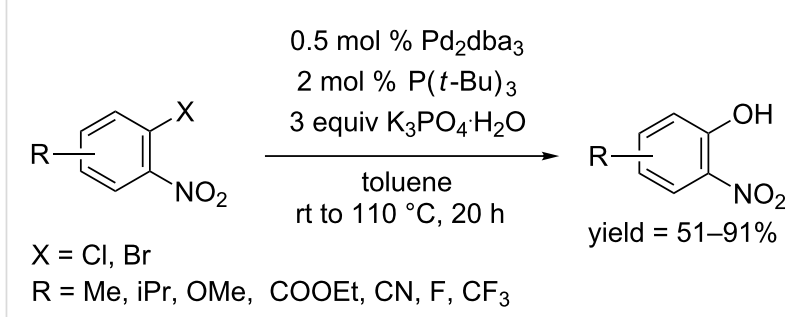

Scheme 2: Hydroxylation of aryl halides using tert-butylphosphine as ligand.

Inspired by a huge effect of the phosphine ligand on the reaction performance, the Beller group synthesized a series of novel imidazole-based phosphine ligands, and their effciency was carefully screened [23]. Among these ligands, the one with two isopropyl groups located at the phenyl ring (L3) was effective in converting aryl chlorides and bromides to the corresponding phenols in moderate to excellent yields (Scheme 3).

The organopalladium complex was so effective that the reactions proceed even at room temperature. Based on their previous work, the Beller group studied all steps of the catalytic cycles and developed a combination of palladium precursor $\left[\mathrm{Pd}(\mathrm{cod})\left(\mathrm{CH}_{2} \mathrm{SiMe}_{3}\right)_{2}\right]$ and $\mathbf{L 3}$, which allowed the reaction to proceed smoothly in THF at room temperature (Scheme 4) [24]. The reaction system used $\mathrm{CsOH}$ as base, providing phenols in moderate to excellent yields.

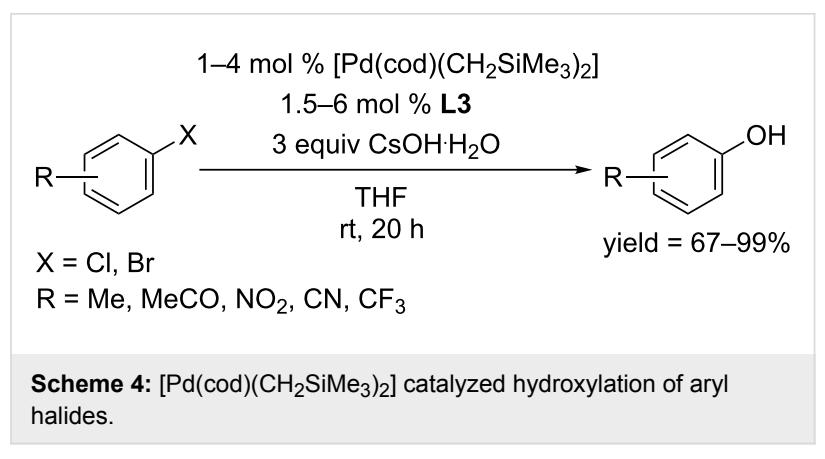

In 2007, the Diaconescu group described Pd/PANI, which was prepared by supporting palladium nanoparticles with polyaniline (PANI) nanofibers. Pd/PANI catalyzed a Suzuki coupling reaction and hydroxylation of aryl halides [25]. The hydroxylation of aryl halides occurred at $100{ }^{\circ} \mathrm{C}$ in aqueous 1,4-dioxane in the presence of $1 \mathrm{~mol} \%$ of Pd/PANI and 4 equiv of $\mathrm{KOH}$ (Scheme 5). Aryl bromide and iodides were converted to the corresponding phenols in good yields.

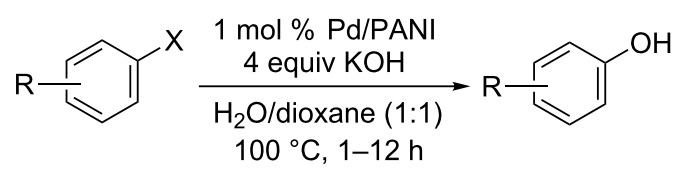

$\mathrm{X}=\mathrm{Cl} ; \mathrm{R}=\mathrm{O}-\mathrm{Me} ;$ yield $=81 \%$
$\mathrm{R}=\mathrm{Br} ; \mathrm{R}=\mathrm{Me}, \mathrm{CN} ;$ yield $=80-90 \%$

Scheme 5: Pd/PANI catalyzed hydroxylation of hydroxylation of aryl halides.

In 2015, Ghorbani-Choghamarani and co-workers designed a new type of nanocatalyst MCM-41-dzt-Pd through the immobilization of $\mathrm{Pd}(\mathrm{OAc})_{2}$ on the surface of dithizone(dzt)-functionalized mesoporous MCM-41 (Scheme 6) [26]. The developed

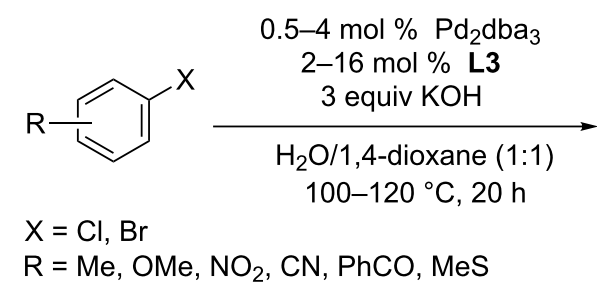<smiles>[R]c1ccc(O)cc1</smiles>

yield $=50-99 \%$<smiles>CC(C)c1cccc(C(C)C)c1-n1ccnc1[Mg]</smiles>

L3 Ad = adamantyl 
catalyst was able to convert aryl halides to the corresponding phenols in water at room temperature. This catalyst can be reused many times without loss of the catalytic activity. Moreover, this catalyst could also be applied in the synthesis of anilines.

$$
\begin{aligned}
& \mathrm{X}=\mathrm{Cl}, \mathrm{Br}, \mathrm{I} \\
& \mathrm{R}=\mathrm{Me}, \mathrm{OMe}, \mathrm{NO}_{2}, \mathrm{CN}
\end{aligned}
$$

Scheme 6: MCM-41-dzt-Pd catalyzed hydroxylation of aryl halides.

\subsubsection{Copper-catalyzed hydroxylation of aryl halides:}

Copper catalysts are considered as economical and stable catalysts. However, copper catalysts often have a low catalytic activity to activate the $\mathrm{C}-\mathrm{Hal}$ bond. Fortunately, along with the development of various bidentate ligands, the copper-catalyzed $\mathrm{C}-\mathrm{O}$ coupling reaction has been extensively applied in the synthesis of phenols from aryl halides. However, the poorer efficiency of copper catalysts than that of palladium catalysts often limits the substrate scope to aryl iodides and aryl bromides.

In 2009, two independent works by Taillerfer and You opened the prelude to the copper-catalyzed hydroxylation of aryl halides. The Taillefer group found that a combination of $\mathrm{CuI}$ and bidentate ligand could promote the conversion of aryl halides to the corresponding phenols in a mixed solvent system of DMSO/ $\mathrm{H}_{2} \mathrm{O}(1: 1)$. Using iodobenzene as model substrate, various ligands were successfully tested: L-proline (yield 70\%), 2-hydroxyacetophenone (yield 85\%), $N, N$-dimethyl-3-oxobutanamide (yield 65\%), tetramethylethylenediamine (TMEDA, yield 84\%), phenanthroline (yield 75\%), 2,2,6,6-tetramethyl3,5-heptanedione (TMHD, yield 95\%) and dibenzoylmethane (L4, yield 97\%) [27,28]. The reaction system afforded phenols from aryl halides and aryl bromides bearing electron-withdrawing groups in moderate to excellent yields (Scheme 7). A broad scope of functional groups was tolerated. They also showed that electron-rich aryl bromides were also converted to phenols via a two-step procedure by addition of sodium iodide. A mechanistic study in the group of Jutand revealed the formation of a copper(I) complex from the 1,2-ketone and the hydroxy group, which further coupled with aryl iodides through oxidative addition to generate a copper(III) complex. Phenols were liberated by the following reductive elimination [29].

You and co-workers used the same copper catalyst and reported that a $N, N$-bidentate ligand, 2,2'-bipyridine (L5) could prompt the conversion of aryl halides to phenols in the presence of $\mathrm{KOH}$ as coupling partner (Scheme 8) [30]. Aryl iodides and electron-deficient aryl bromides were easily converted to the corresponding phenols in good to excellent yields. A broad scope of functional groups including ether, halo, hydroxy, carboxylic acid and trifluoromethyl groups were well tolerated in their protocol. Even hindered substrates such as 2,6-diisopropyl iodobenzene also afforded the corresponding phenol in

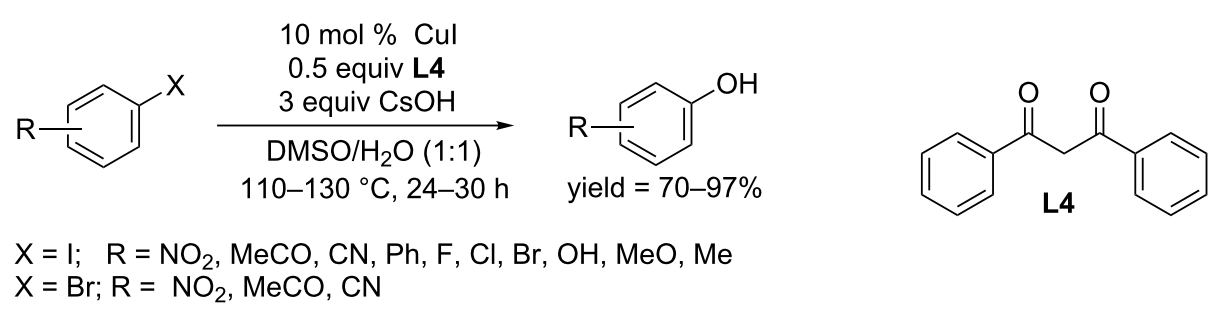

Scheme 7: Hydroxylation of aryl halides using dibenzoylmethane as ligand.

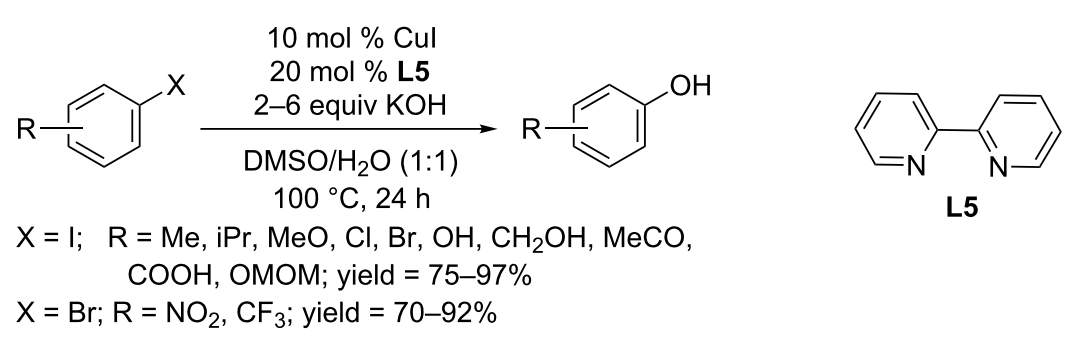

Scheme 8: Hydroxylation of aryl halides using 2,2'-bipyridine as ligand. 
satisfying yield. The developed protocol was further applied in the synthesis of alkyl aryl ethers and benzofurans, which often possess interesting biological activities.

In 2011, the Zhang and Ma group screened a series of 2-heteroarylpyridines and found another $N, N$-bidentate ligand, 5-bromo-2-(1H-imidazol-2-yl)pyridine (L6), and succeeded to synthesize phenols from aryl bromides in the presence of $\mathrm{CuI}$ as catalyst in the mixed solvent of $t$ - $\mathrm{BuOH}-\mathrm{DMSO}-\mathrm{H}_{2} \mathrm{O}$ at $120^{\circ} \mathrm{C}$ (Scheme 9) [31]. Both electron-rich and electron-deficient aryl bromides were converted to the corresponding phenols in good to excellent yields. Under the optimum conditions, switching the base $\mathrm{CsOH}$ to weaker $\mathrm{KOH}$ showed comparable yields.

In 2010, Leadbeater and co-workers used $N, N^{\prime}$-dimethylethylenediamine (DMEDA) as ligand and performed the reaction using $\mathrm{CuI}$ as catalyst in the presence of $\mathrm{K}_{3} \mathrm{PO}_{4}$ [32] (Scheme 10). Under microwave heating, the reactions were accomplished within $30 \mathrm{~min}$. A variety of aryl halides were converted to the corresponding phenols.

Fu and co-workers employed pyridine-2-aldoxime (PAO, L7) as ligand and developed a $\mathrm{Cu}_{2} \mathrm{O}$ catalyzed hydroxylation protocol [33]. The reaction was carried out at $110{ }^{\circ} \mathrm{C}$ in water in the presence of $n-\mathrm{Bu}_{4} \mathrm{NBr}$ as phase transfer catalyst (Scheme 11). Aryl iodides and electron-deficient aryl bromides and chlorides were converted to the corresponding phenols. A

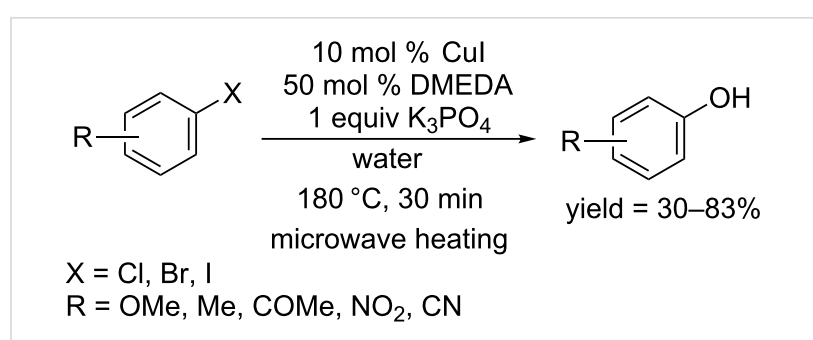

Scheme 10: Hydroxylation of aryl halides using DMEDA as ligand.

broad range of functional groups are well tolerated under their optimum condition.

Besides the opening work using TMHD by the Taillefer group, other O,O-bidentate ligands also played important roles in $\mathrm{C}-\mathrm{O}$ coupling reactions for the synthesis of phenols from aryl halides.

In 2011, the Sekar group used D-glucose as ligand and reported a $\mathrm{Cu}(\mathrm{OAc})_{2}$ catalyzed synthesis of phenols from aryl halides in the presence of $\mathrm{KOH}$ in $\mathrm{DMSO} / \mathrm{H}_{2} \mathrm{O}(1: 1)$ at $120{ }^{\circ} \mathrm{C}$ (Scheme 12) [34]. Aryl iodides and electron-deficient aryl bromides provided good to excellent yields. D-Glucose represents a type of environmentally friendly ligand and can be easily removed during the work-up process. This work is of special value as it was the first report employing copper(II) as the catalyst in the synthesis of phenols.

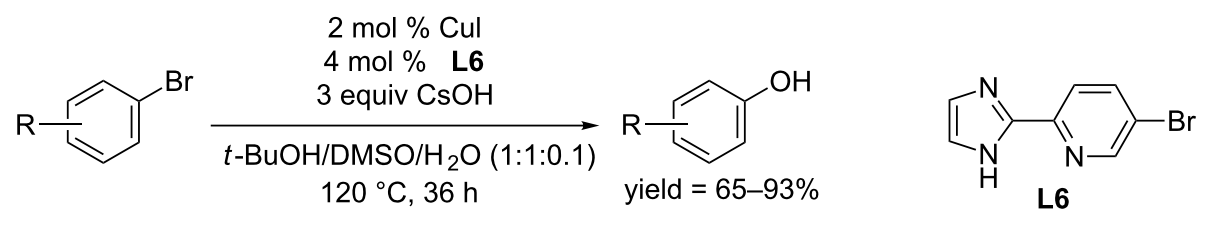

$\mathrm{R}=\mathrm{F}, \mathrm{Cl}, \mathrm{CN}, \mathrm{Me}, \mathrm{OMe}, \mathrm{NO}_{2}, \mathrm{CH}_{2} \mathrm{OH}, \mathrm{Ph}, \mathrm{OH}, \mathrm{CHO}, \mathrm{MeCO}, \mathrm{COOH}, \mathrm{COOMe}$

Scheme 9: Hydroxylation of aryl bromides using imidazolyl pyridine as ligand.

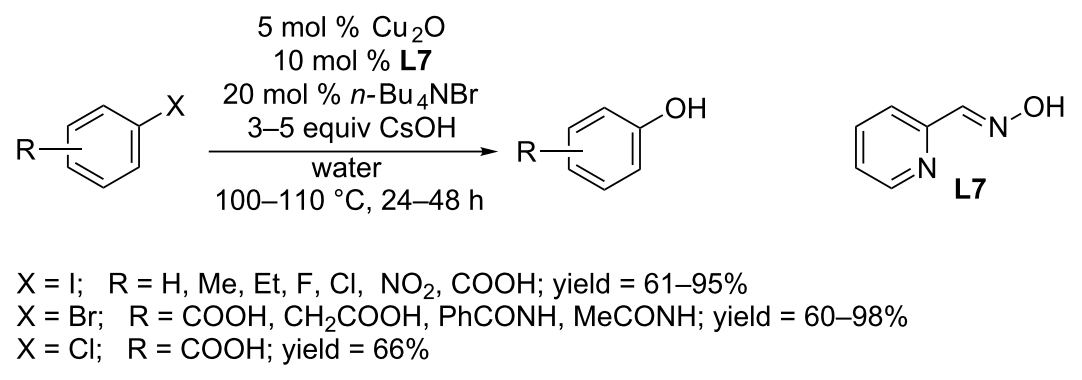

Scheme 11: Hydroxylation of aryl halides using PAO as ligand. 


$$
\begin{aligned}
& 5 \mathrm{~mol} \% \mathrm{Cu}(\mathrm{OAc})_{2} \cdot \mathrm{H}_{2} \mathrm{O}
\end{aligned}
$$

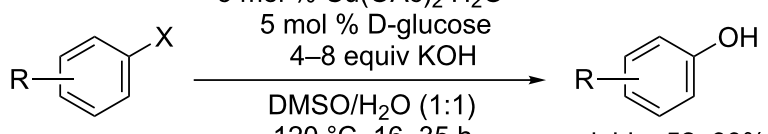

$$
\begin{aligned}
& \mathrm{X}=\mathrm{I}, \mathrm{Br}, \mathrm{Cl} \\
& 120^{\circ} \mathrm{C}, 16-35 \mathrm{~h} \\
& \text { yield }=52-99 \%
\end{aligned}
$$

Scheme 12: Hydroxylation of aryl halides using D-glucose as ligand.

In 2011, the Maheswaran group used the sulfonic acid resin INDION-770 as additive and developed a CuI-catalyzed protocol for the hydroxylation of aryl halides in a DMSO $/ \mathrm{H}_{2} \mathrm{O}$ (2:1) solvent system (Scheme 13) [35]. In this heterogeneous reaction system, the cation of $\mathrm{CuI}$ was attached to the sulfonic acid resin, and could be easily recovered and reused. Aryl iodides, activated aryl bromides and chlorides, and heteroaryl bromides were smoothly converted to phenols.

$$
\begin{aligned}
& 0.1 \mathrm{~mol} \% \mathrm{Cul} \\
& 3 \text { equiv } \mathrm{CsOH} \\
& \text { } \\
& 60 \mathrm{mg} \text { INDION } 770 \text { in } \\
& 1 \mathrm{mmol} \text { scale } \\
& \text { DMSO/ } \mathrm{H}_{2} \mathrm{O}(2: 1) \\
& 100-130^{\circ} \mathrm{C}, 24 \mathrm{~h} \\
& \mathrm{X}=\mathrm{I}, \mathrm{Br}, \mathrm{Cl} \\
& \mathrm{R}=\mathrm{Me}, t-\mathrm{Bu}, \mathrm{Cl}, \mathrm{OH}, \mathrm{OMe}, \mathrm{COMe}, \mathrm{NO}_{2}, \mathrm{CF}_{3}
\end{aligned}
$$

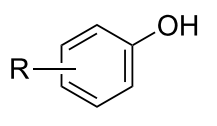

Scheme 13: Hydroxylation of aryl halides using INDION-770 as ligand

In 2011, the Chen group developed a PEG-400-mediated protocol for the synthesis of phenols using $\mathrm{CuI}$ as the catalyst and $\mathrm{KOH}$ as the base (Scheme 14) [36]. In this reaction system, non-toxic and cheap PEG-400 played a dual role as both ligand and solvent. The effective catalytic system could convert aryl iodide to phenols in high yields within 5 hours at $100{ }^{\circ} \mathrm{C}$. The conversion of aryl bromides bearing either an electron-donating group or an electron-withdrawing group required higher temperatures $\left(120^{\circ} \mathrm{C}\right)$ and a longer reaction time ( 8 hours).

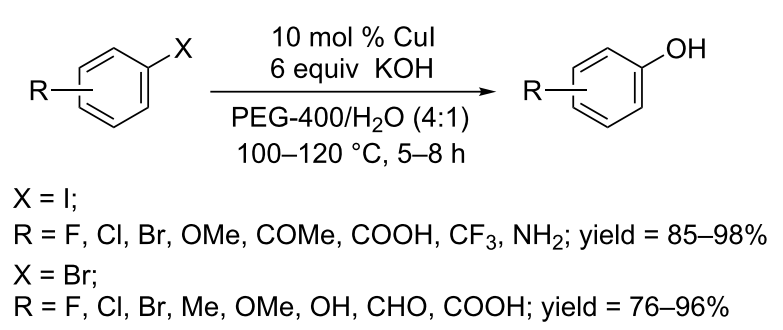

Scheme 14: PEG-400 mediated hydroxylation of aryl halides.

In 2013, the Chae group reported that a simple ligand, glycolic acid, could promote the conversion of aryl halides to phenols in the presence of $\mathrm{Cu}(\mathrm{OH})_{2}$ and $\mathrm{NaOH}$ in the solvent of DMSO/ $\mathrm{H}_{2} \mathrm{O}$ (1:1) (Scheme 15) [37]. Aryl iodides can give the corresponding phenols in excellent yields. Typically, the orthobromo group was not affected under standard conditions for the conversion of aryl iodides. Electron-deficient aryl bromides were converted by increasing the catalyst loading to $10 \mathrm{~mol} \%$ or extending the reaction time. Interestingly, a similar catalytic system using $\mathrm{CuI}$ as catalyst and $\mathrm{Cs}_{2} \mathrm{CO}_{3}$ as base predominantly afforded ethers rather than phenols.

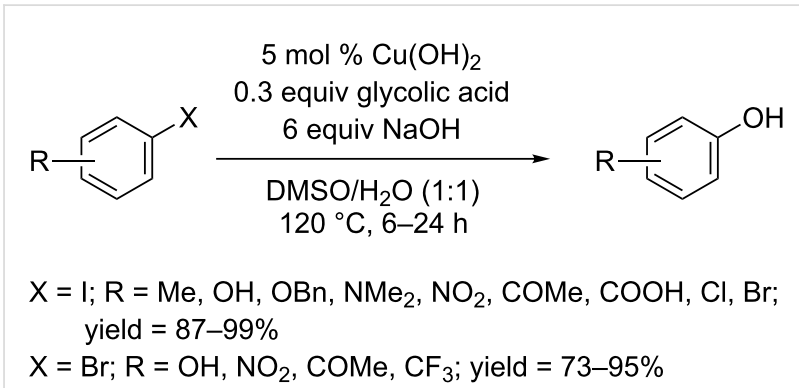

Scheme 15: Hydroxylation of aryl halides using glycolic acid as ligand.

In 2015, the Wang group employed $\mathrm{CuSO}_{4} \cdot 5 \mathrm{H}_{2} \mathrm{O}$ as catalyst and screened a series of ligands, revealing that L-sodium ascorbate (L8) could promote the synthesis of phenols (Scheme 16) [38]. The reaction occurred at $120^{\circ} \mathrm{C}$ in the presence of $\mathrm{KOH}$

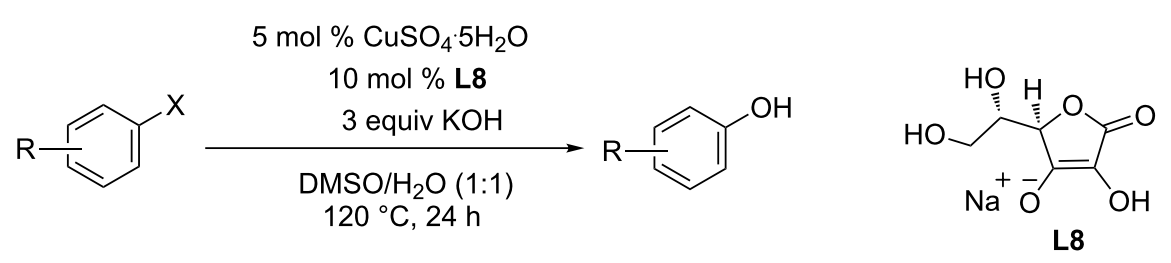

$\mathrm{X}=\mathrm{I} ; \mathrm{R}=\mathrm{Me}, \mathrm{OMe}, \mathrm{Cl}, \mathrm{Br}, \mathrm{NO}_{2}, \mathrm{COOH} ;$ yield $=78-92 \%$

$\mathrm{X}=\mathrm{Br} ; \mathrm{R}=\mathrm{Cl}, \mathrm{Me}, \mathrm{NO}_{2} ;$ yield $=64-75 \%$

$X=\mathrm{Cl} ; \mathrm{R}=\mathrm{NO}_{2} ;$ yield $=63-76 \%$ 
as base, converting aryl iodides and nitro-substituted aryl bromides and chlorides to the corresponding phenols in moderate yields.

Phenols can be obtained from phenyloxylethanols through an intramolecular nucleophilic substitution [39]. In 2015, the Chae group found difunctionalized ethanes including 2-dimethylaminoethanol and ethylene glycol can function as ligand to work with $\mathrm{Cu}(\mathrm{OAc})_{2}$ in the presence of $\mathrm{KOH}$, affording phenols from aryl iodides in moderate to excellent yields (Scheme 17) [40].

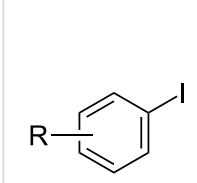

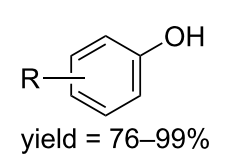

$\mathrm{R}=\mathrm{Me}, \mathrm{OH}, \mathrm{OMe}, \mathrm{COMe}, \mathrm{COOH}, \mathrm{F}, \mathrm{Cl}, \mathrm{NO}_{2}, \mathrm{CF}_{3}$

$10 \mathrm{~mol} \% \mathrm{Cu}_{2} \mathrm{O}$

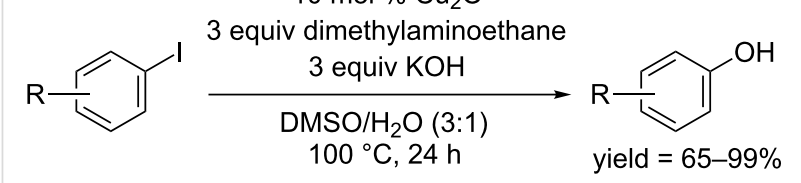

$\mathrm{R}=\mathrm{Me}, \mathrm{OH}, \mathrm{OMe}, \mathrm{COOH}, \mathrm{F}, \mathrm{Cl}, \mathrm{NO}_{2}, \mathrm{CF}_{3}$

Scheme 17: Difunctionalized ethanes mediated hydroxylation of aryl iodides.

In 2010, a screening work for the ligand by the Punniyamurthy group led to the discovery of a new type of N,O-bidentate ligand, 2-methyl-8-hydroxyquinoline (L9), which could promote the CuI-catalyzed hydroxylation of aryl halides in the presence of $n-\mathrm{Bu}_{4} \mathrm{NOH} \cdot 5 \mathrm{H}_{2} \mathrm{O}$ without a strong base (Scheme 18) [41]. Remarkably, aryl bromides bearing either an electron-donating group or an electron-withdrawing group were converted to the corresponding phenols in excellent yields. In the same year, the Jiang and Ma group found 8-hydroxyquinoline could function as ligand in the hydroxylation of aryl iodides in the presence of $\mathrm{CuI}$ as catalyst and $\mathrm{KOH}$ as base [42].

In 2011, the Jiang group employed 8-hydroxyquinoline- $N$-oxide (L10) as ligand and hydroxylation occurred in the presence of $\mathrm{CuI}$ as catalyst and $\mathrm{CsOH}$ as base (Scheme 19) [43]. The catalytic activity of the reaction system depended on the reaction temperature. The reactions of aryl iodides and aryl bromides were carried out at $100{ }^{\circ} \mathrm{C}$ and $110^{\circ} \mathrm{C}$, respectively. The conversion of aryl chlorides bearing electron-withdrawing groups was achieved at $130{ }^{\circ} \mathrm{C}$.

Amino acids and its analogues are another type of N,O-bidentate ligand for copper catalyzed hydroxylation of aryl halides. In 2010, the Zhou group developed a CuI catalyzed protocol for hydroxylation of aryl iodides and bromides using lithium pipecolinate (L11) as ligand, yielding phenols in moderate to good yields (Scheme 20) [44]. The reaction proceeded in the presence of $(n-\mathrm{Bu})_{4} \mathrm{NF}$ and $\mathrm{NaOH}$. Notably, the reaction was carried out in water, avoiding the use of an organic solvent. In addition, a broad substrate scope was observed; some sensitive functional groups, such as carboxylic acid, aldehyde and cyano were well tolerated.

In 2013, the Zhou group used lithium L-prolinate (L12) as ligand and developed a $\mathrm{CuCl}_{2}$ catalyzed protocol for converting aryl halides to phenols [45]. Aided by $200 \mathrm{~W}$ microwave irradi-

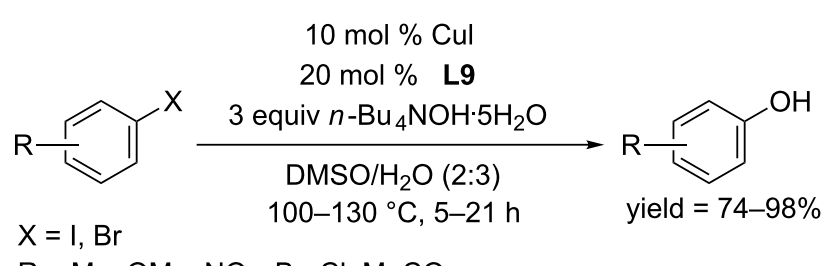

$\mathrm{R}=\mathrm{Me}, \mathrm{OMe}, \mathrm{NO}_{2}, \mathrm{Br}, \mathrm{Cl}, \mathrm{MeCO}$<smiles>Cc1ccc2cccc(O)c2n1</smiles>

L9

Scheme 18: Hydroxylation of aryl halides using 2-methyl-8-hydroxylquinoline as ligand.

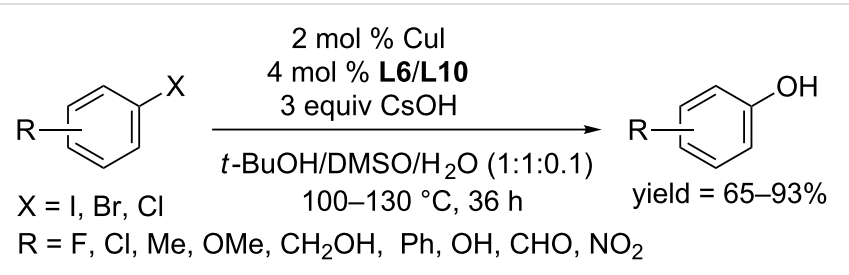<smiles>[O-][n+]1cccc2cccc(O)c21</smiles>

L10 


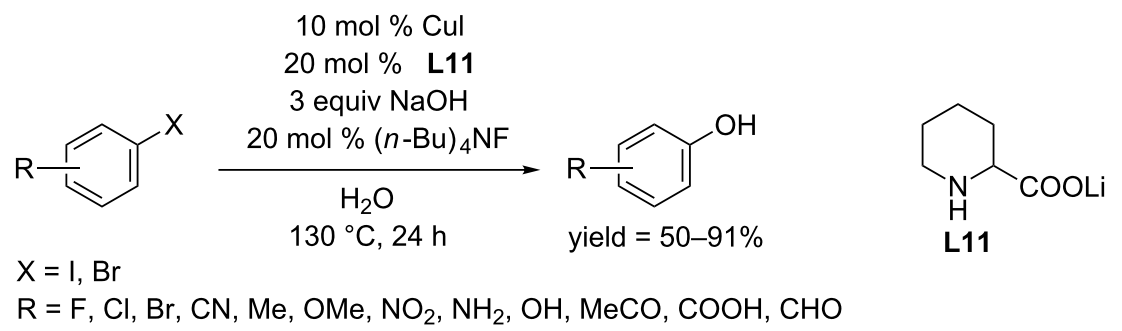

Scheme 20: Hydroxylation of aryl halides using lithium pipecolinate as ligand.

ation, the conversion was accomplished within 40 minutes in the presence of $(n-\mathrm{Bu})_{4} \mathrm{NBr}$ and $\mathrm{KOH}$ (Scheme 21). Using this reaction system, moderate yields of phenols could be obtained from both aryl iodides and aryl bromides. It is surprising that iodobenzenes bearing para-substitutes including methyl, methoxyl, cyano and bromo gave benzene as product rather than the corresponding phenols.

In 2014, the Wang group found triethanolamine (L13) could serve as ligand to synthesize phenols from aryl iodides and bromides in water using $\mathrm{CuI}$ as catalyst (Scheme 22) [46]. In the presence of $\mathrm{KOH}$, aryl iodides containing both electron-donating and electron-withdrawing groups afforded the corresponding phenols in good to excellent yields. Aryl bromides were converted in good yields when treated with stronger base $\mathrm{CsOH}$ at $145^{\circ} \mathrm{C}$.
Although the ligand highly increased the catalytic activity of the copper catalyst, it was often used in large amount, making the process expensive and difficult in removing it. In this context, some ligand-free protocols have been developed by enhancing the reaction activity in some other ways.

In 2011, the Xu and Feng group cooperatively reported the hydroxylation of aryl halides without ligand using CuI-nanoparticles as catalyst in the presence of $(n-\mathrm{Bu})_{4} \mathrm{NBr}$ under very mild conditions [47]. CuI-nanoparticles could be reused with a slight loss of activity. The reaction was carried out in water at $60-80{ }^{\circ} \mathrm{C}$, affording the phenols from aryl iodides and bromides in good to excellent yields (Scheme 23). In the case of aryl bromide, long reaction time $(48 \mathrm{~h})$ was required. $110 \mathrm{~mol} \%$ of CuI-nanoparticles was needed for the complete conversion of aryl bromides bearing electron-donating groups.

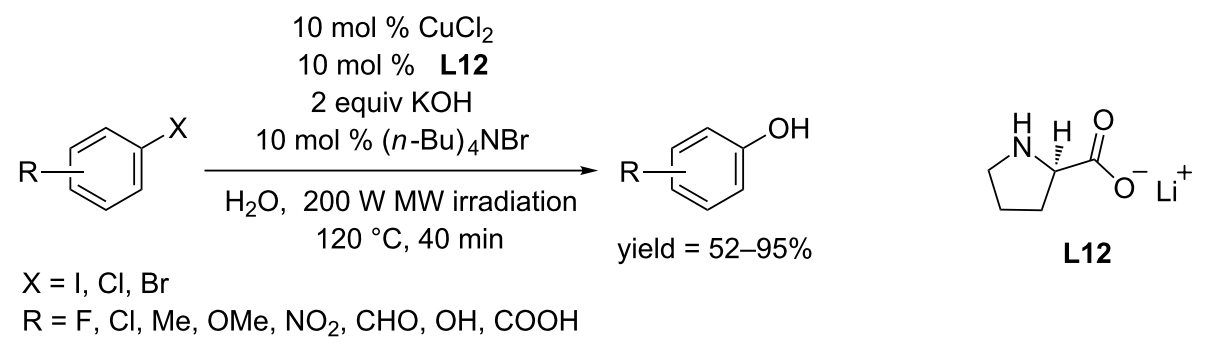

Scheme 21: Hydroxylation of aryl halides using L-lithium prolinate.

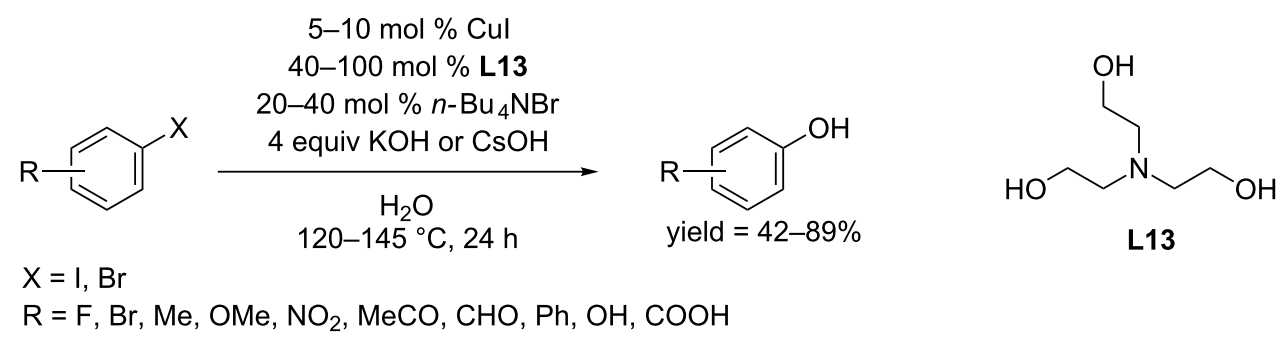

Scheme 22: Hydroxylation of aryl halides using triethanolamine as ligand. 
It's worth noting that the developed protocol could be easily applied to the synthesis of anilines and aryl thiols.

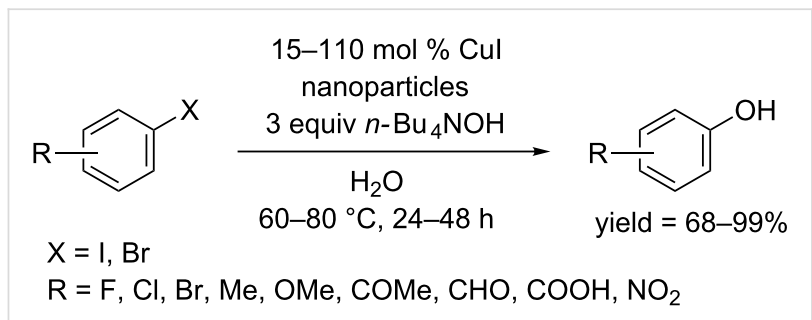

Scheme 23: Cul-nanoparticle-catalyzed hydroxylation of aryl halides.

In 2014, the Jiang and Han group used a copper-doped graphitic carbon nitride catalyst $\mathrm{Cu}-\mathrm{g}-\mathrm{C}_{3} \mathrm{~N}_{4}$, which was prepared from urea and $\mathrm{CuNO}_{3}$, and developed a ligand free protocol for the synthesis of phenols from aryl iodides [48]. The conversion was achieved smoothly in the presence of $\mathrm{NaOH}$ in a mixed solvent of DMSO and $\mathrm{H}_{2} \mathrm{O}$ (Scheme 24).

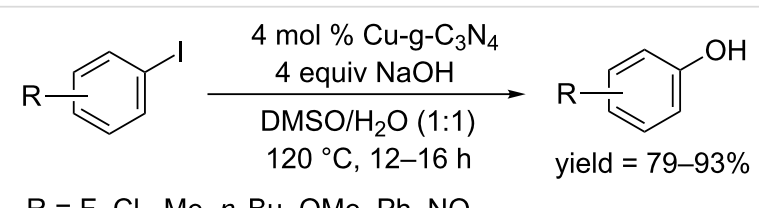

$\mathrm{R}=\mathrm{F}, \mathrm{Cl}, \mathrm{Me}, n-\mathrm{Bu}, \mathrm{OMe}, \mathrm{Ph}, \mathrm{NO}_{2}$

Scheme 24: Cu-g- $\mathrm{C}_{3} \mathrm{~N}_{4}$-catalyzed hydroxylation of aryl bromides.

As described above, both palladium and copper catalysts have shown promising effectivenesses in catalyzing the conversion of aryl halides to phenols. Generally, copper catalysts are more favorable for aryl bromides and aryl iodides as aryl chlorides require palladium catalysts. Except for special cases, a ligand is indispensable for the conversion. In the view of solvent, $\mathrm{DMSO} / \mathrm{H}_{2} \mathrm{O}$ as mixed solvent or water as sole solvent are popular choices for the hydroxylation of aryl halides.

\subsection{Arenes as substrate}

It has been a long time since $\mathrm{C}-\mathrm{H}$ hydroxylation first appeared, however, in the beginning it often suffered from some drawbacks such as low selectivity and low yield. In 1991, the Fujiwara group showed the possibility of preparing phenol from benzene using $\mathrm{Pd}(\mathrm{OAc})_{2}$ as catalyst and molecular oxygen as oxidant, however, the reaction suffered from low yield $(2.3 \%)$ $[49,50]$. In 1997, Seo and co-workers reported an iron-HPA (heteropoly acid)-complex-catalyzed protocol for oxidation of benzene to phenol [51]. In 2005, the Rybak-Akimova group reported that they used a stoichiometric amount of reactive iron complex $\left[\mathrm{Fe}(\mathrm{II})(\mathrm{BPMEN})\left(\mathrm{CH}_{3} \mathrm{CN}\right)_{2}\right]\left(\mathrm{ClO}_{4}\right)_{2}$ to achieve orthohydroxylation of benzoic acid in the presence of $\mathrm{H}_{2} \mathrm{O}_{2}$, affording salicylic acid in low yields [52]. In the past decade, the selectivity and yield of $\mathrm{C}-\mathrm{H}$ hydroxylation of arenes were highly improved by introduction of various directing groups.

\subsubsection{Copper mediated $\mathrm{C}-\mathrm{H}$ hydroxylation of arenes: A} breakthrough was made by $\mathrm{Yu}$ and co-workers in 2006. They reported a protocol for the hydroxylation of (2-pyridyl)arenes [53]. Under an atmosphere of oxygen, the reaction proceeded in the presence of a stoichiometric amount of $\mathrm{Cu}(\mathrm{OAc})_{2}$ and $\mathrm{H}_{2} \mathrm{O}$ in acetonitrile at $130{ }^{\circ} \mathrm{C}$, and the resulting acetate gave phenols in moderate yields through a simple hydrolysis (Scheme 25). A mechanistic investigation revealed that the reaction proceeded via a radical-cation pathway. Notably, their protocol could be also applied in the chlorination and other $\mathrm{C}-\mathrm{H}$ functionalization of (2-pyridyl)arenes. Together with this work, some other work on $\mathrm{C}-\mathrm{H}$ acyloxylation provided an indirect pathway for the synthesis of phenols from arenes [54].

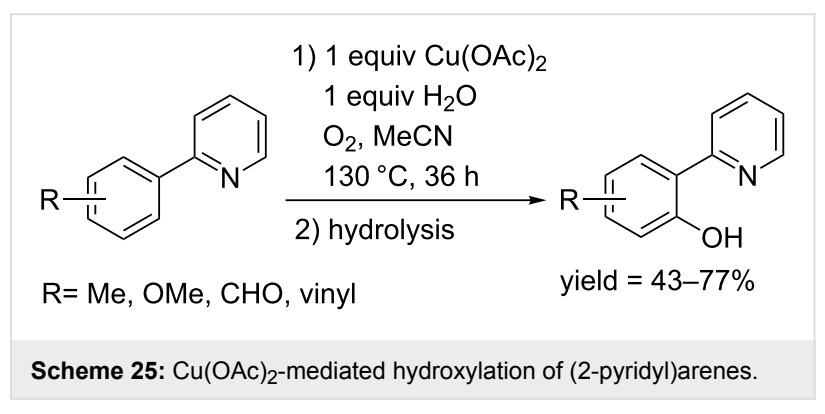

In 2014, Shi and co-workers designed a removable bidentate functional group, which could facilitate $\mathrm{C}-\mathrm{H}$ hydroxylation of benzoic acids and heteroarenes [55]. An amidation reaction between benzoic acid and 2-(pyridine-2-yl)isopropylamine gave $N$-(2-(pyridine-2-yl)isopropyl)benzamides, which could be hydroxylated at the ortho position in moderate to excellent yields. The reaction was promoted by a stoichiometric amount of $\mathrm{Cu}(\mathrm{OAc})_{2}$ in the presence of $\mathrm{Ag}_{2} \mathrm{CO}_{3}$ and TBAI as additives in DMF at $100{ }^{\circ} \mathrm{C}$ (Scheme 26). Notably, their protocol was so efficient that the reactions could accomplish within 1 hour. The substrate scope showed benzamides bearing both electron-donating groups and electron-withdrawing groups were converted to the corresponding phenols. Moreover, heteroarenes, such as pyridine and thiophenes, could also give hydroxylated products under their conditions.

In 2016, Jana and co-workers used $N$-(8-quinolinyl)benzamides as starting materials, and ortho-hydroxylation occurred in the presence of a stoichiometric amount of $\mathrm{Cu}(\mathrm{OAc})_{2}$ and pyridine in DMSO/DMF (1:3) (Scheme 27) [56]. Hydroxylation of arenes could be accomplished within 2 hours. Both electron-donating groups and electron-withdrawing groups were well tolerated. The developed protocol could be also applied in the hydroxylation of aryl halides and aryl methyl ethers. 


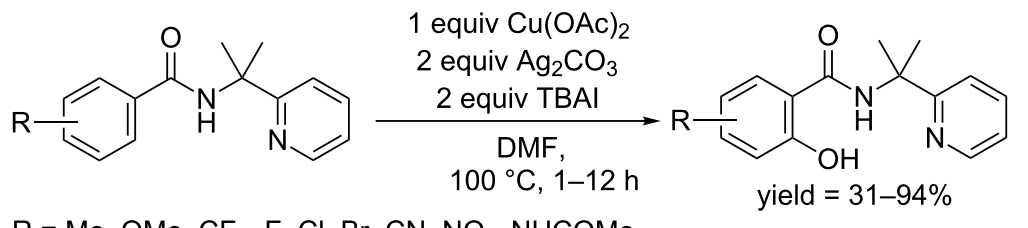

$\mathrm{R}=\mathrm{Me}, \mathrm{OMe} \mathrm{CF}_{3}, \mathrm{~F}, \mathrm{Cl}, \mathrm{Br}, \mathrm{CN}, \mathrm{NO}_{2}, \mathrm{NHCOMe}^{-}$

Scheme 26: Removable pyridine moiety directed hydroxylation of arenes.

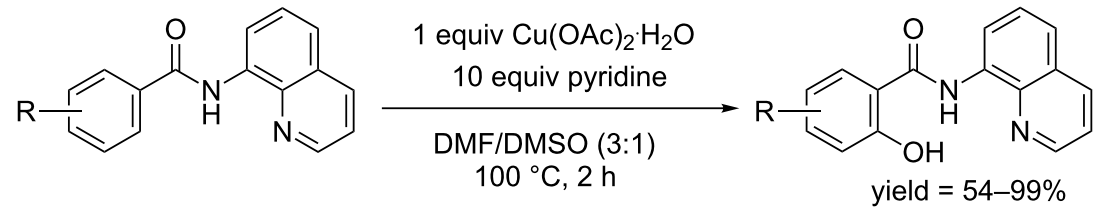

$\mathrm{R}=\mathrm{F}, \mathrm{Cl}, \mathrm{Br}, \mathrm{I}, \mathrm{CF}_{3}, \mathrm{NO}_{2}, \mathrm{Me}, \mathrm{MeS}, \mathrm{Ph}, \mathrm{MeCO}, n-\mathrm{Bu}$, etc.

Scheme 27: Removable quinoline moiety directed hydroxylation of arenes.

Several examples using catalytic amounts of copper catalyst have also been reported. In 2012, the Lei group developed mild conditions using a catalytic amount of $\mathrm{CuCl}_{2}$ to convert heterocycles to the hydroxylated products in the presence of $\mathrm{NaO} t$-Bu in the air at room temperature (Scheme 28) [57]. Muti-halogenated arenes also gave the corresponding phenols when treated under the above mentiond conditions. An mechanistic investigation showed that $\mathrm{NaO} t$-Bu was a crucial reagent which played dual roles in affording the active $\mathrm{CuO} t-\mathrm{Bu}$ from $\mathrm{CuCl}_{2}$, and deprotonation of heteroarenes before the formation of copper complex.

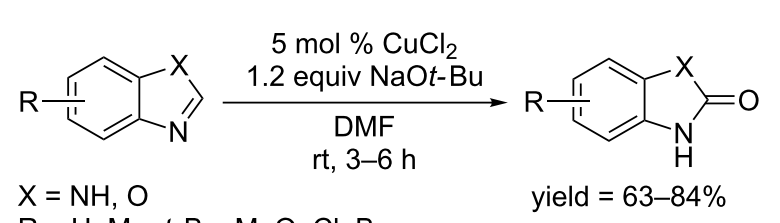

Scheme 28: $\mathrm{CuCl}_{2}$ catalyzed hydroxylation of benzimidazoles and benzoxazoles.
In 2016, the Wang and Shi group reported a CuI-catalyzed C-H hydroxylation of thiophenols, in which disulfide directed the hydroxylation [58]. Using aryl thiol and arylboronic acid as starting materials, $\mathrm{C}-\mathrm{H}$ hydroxylation and $\mathrm{C}-\mathrm{S}$ coupling sequentially occurred in DMF in the presence of $\mathrm{Cs}_{2} \mathrm{CO}_{3}$ and molecular oxygen, affording 2-(phenylthio)phenols as final products (Scheme 29). A preliminary mechanistic study showed that molecular oxygen participated in the formation of the hydroxy group. This protocol was further applied to the synthesis of quinines.

1.2.2 Palladium-catalyzed $\mathrm{C}-\mathrm{H}$ hydroxylation of arenes: Palladium catalysts were proved to be effective in catalyzing $\mathrm{C}-\mathrm{H}$ hydroxylation of arenes and a variety of directing groups have been extensively studied and demonstrated to work as designed, thus providing plenty of strategies toward the preparation of phenols from arenes.

1.2.2.1 Pyridine and nitrogen containing functional groups as directing groups: In 2008, Kim and co-workers synthesized a series of 2-arylpyridines, in which another aryl group was lo-

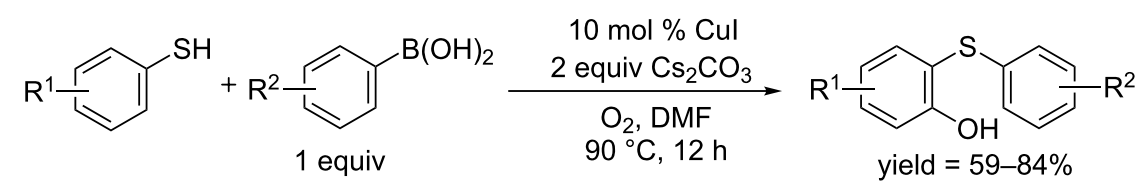

$\mathrm{R}^{1}=\mathrm{H}, \mathrm{F}, \mathrm{Cl}, \mathrm{Br}, \mathrm{CF}_{3}, \mathrm{OMe}$;

$\mathrm{R}^{2}=\mathrm{F}, \mathrm{Br}, \mathrm{I}, \mathrm{Me}, \mathrm{OMe}, \mathrm{Et}, \mathrm{OEt}, t-\mathrm{Bu}, \mathrm{COOMe}$ 
cated at 3-position and a benzyl group at 5-position of the pyridine ring. Then they developed a $\mathrm{Pd}(\mathrm{OAc})_{2}$-catalyzed orthohydroxylation of the synthesized diarylpyridines [59]. Their protocol employed oxone as oxidant, allowing the conversion to complete within 2 hours in PEG-3400/t-BuOH at $80-90{ }^{\circ} \mathrm{C}$ (Scheme 30). By employing their protocol, ortho-hydroxyarenes were predominately formed. This method did not work with ortho-substituted arenes.

In 2013, Jiao and co-workers reported a hydroxylation protocol for (2-pyridyl)arenes using $\mathrm{PdCl}_{2}$ and $\mathrm{N}$-hydroxyphthalimide (NHPI) as catalyst and molecular oxygen as oxidant [60]. (2-Pyridyl)arenes were converted to the hydroxylated products in toluene at $100^{\circ} \mathrm{C}$ (Scheme 31$)$.

In 2015, Itoh and co-workers employed $\mathrm{PdCl}_{2}$ as catalyst and the hydroxylation of arylpyridines was carried out in 4-methyl2-pentanone at $100{ }^{\circ} \mathrm{C}$ in the presence of $\mathrm{H}_{2} \mathrm{O}_{2}$ (Scheme 32)
[61]. In terms of reactivity, substituent at the para-position of the phenyl ring is more favored than at other positions.

In 2015, Sun and co-workers developed a $\mathrm{Pd}(\mathrm{OAc})_{2}$ catalyzed ortho-hydroxylation of 2-arylpyridines using tert-butyl hydroperoxide (TBHP) as oxidant [62]. The reaction was carried out at $115{ }^{\circ} \mathrm{C}$ in 1,2-dichloroethane (DCE), affording the corresponding phenols in moderate to good yields (Scheme 33). The reaction yield were lowered by adding a radical-trapping reagent, 2,2,6,6-tetramethyl-1-piperidinyloxy (TEMPO), indicating that radical $\mathrm{HO}$, which was generated from TBHP, may participate in the oxidation of the palladium complex from $\mathrm{Pd}(\mathrm{II})$ to $\mathrm{Pd}(\mathrm{IV})$.

In 2016, Guin and co-workers described a $\mathrm{Pd}\left(\mathrm{CH}_{3} \mathrm{CN}\right)_{2} \mathrm{Cl}_{2}$ catalyzed $\mathrm{C}-\mathrm{H}$ hydroxylation of 2-arylpyridines using molecular oxygen as oxidant [63]. The conversion was achieved in the presence of $n$-butyraldehyde in DCE at $100{ }^{\circ} \mathrm{C}$, affording<smiles>[R]c1ccc(-c2cc(Cc3ccccc3)c(C)nc2-c2ccc([R])cc2)cc1</smiles>

$\mathrm{R}^{1}=\mathrm{H}, \mathrm{Cl}, \mathrm{Me}, \mathrm{MeO}$

$\mathrm{R}^{2}=\mathrm{Cl}, \mathrm{MeO}$

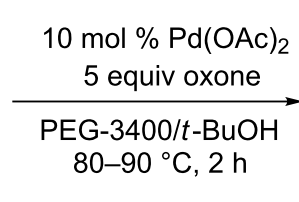

5 equiv oxone

$80-90^{\circ} \mathrm{C}, 2 \mathrm{~h}$

Scheme 30: $\mathrm{Pd}(\mathrm{OAc})_{2}$-catalyzed hydroxylation of diarylpyridines.

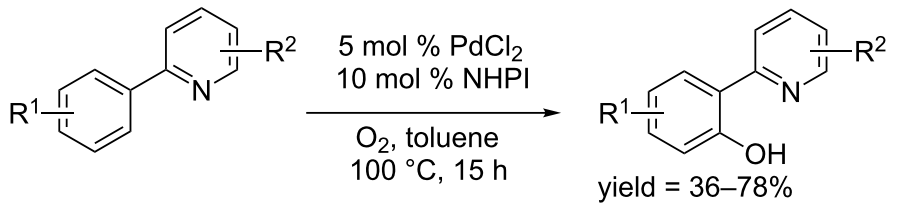

$\mathrm{R}^{1}=\mathrm{H}, \mathrm{F}, \mathrm{Cl}, \mathrm{Me}, \mathrm{iPr}, \mathrm{Ph}, \mathrm{CF}_{3}, \mathrm{OEt}, \mathrm{OPh}, \mathrm{On}-\mathrm{Bu}, \mathrm{OiPr}$

$\mathrm{R}^{2}=\mathrm{H}, \mathrm{Me}, \mathrm{OMe}$

Scheme 31: $\mathrm{PdCl}_{2}$-catalyzed hydroxylation of 2-arylpyridines.

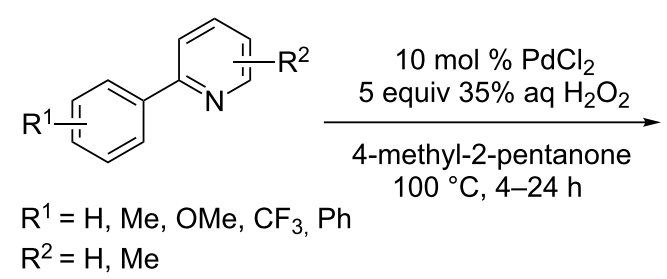

yield $=12-74 \%$

yield $=28-76 \%$<smiles>[R]CN([R])c1ccc(-c2cc(Cc3ccccc3)c(C)nc2-c2ccc([R])cc2)cc1</smiles>

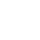


<smiles>[R]c1ccc(-c2ccccn2)cc1</smiles>
$\begin{gathered}5 \mathrm{~mol} \% \mathrm{Pd}(\mathrm{OAc})_{2} \\ 6 \text { equiv TBHP }\end{gathered}$
$\underset{\mathrm{DCE}, 115^{\circ} \mathrm{C}, 20 \mathrm{~h}}{\longrightarrow}$

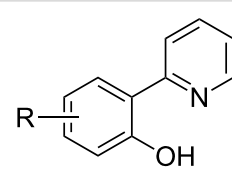

yield $=51-88 \%$
$\mathrm{R}=\mathrm{F}, \mathrm{Cl}, \mathrm{Br}, \mathrm{CF}_{3}, \mathrm{OCF}_{3}, \mathrm{NO}_{2}, \mathrm{COOMe}$, COOEt, OMe, Me, $\mathrm{Ph}, \mathrm{Et}, t-\mathrm{Bu}$, etc.

Scheme 33: $\mathrm{Pd}(\mathrm{OAc})_{2}$-catalyzed hydroxylation of 2-arylpyridines.

substituted 2-(pyridin-2-yl)phenols in good yields (Scheme 34). This protocol also involved radical species, such as an active acylperoxo-radical generated from oxygen and $n$-butyraldehyde. On both the phenyl ring or on the pyridine ring, electron-donating and electron-withdrawing groups were tolerated, respectively, although electron-deficient substrates required longer reaction time.

In 2013, Patel and co-workers succeeded in ortho-hydroxylation of 2-arylbenzothiazoles [64]. Directed by the benzothiazolyl group, $\mathrm{Pd}(\mathrm{OAc})_{2}$ catalyzed $\mathrm{C}-\mathrm{H}$ hydroxylation occurred in acetic acid at $110{ }^{\circ} \mathrm{C}$ in the presence of diacetoxyiodobenzene (DIB) as oxidant (Scheme 35). Both electron-withdrawing groups and electron-donating groups are well tolerated and the protocol gave phenols in moderate to excellent yields. The analysis of the reaction performances indicated that the reaction proceeded through a $\mathrm{Pd}(\mathrm{II}) / \mathrm{Pd}(\mathrm{IV})$ catalytic cycle.

In 2014, a $\mathrm{Pd}(\mathrm{OAc})_{2}$ catalyzed protocol for the hydroxylation of 2-arylbenzimidazoles was developed by the Kamal and Nagesh group [65]. In their reaction system, oxone was used as oxidant, $\mathrm{Cs}_{2} \mathrm{CO}_{3}$ as base and DMF as solvent (Scheme 36). The reaction occurred at $120{ }^{\circ} \mathrm{C}$ and afforded the corresponding phenols in moderate yields. The catalytic system could also be used for alkoxylation of 2-arylbenzimidazoles when the solvent was replaced by aliphatic alcohols.

In 2015, Chakraborti and co-workers developed a $\mathrm{Pd}(\mathrm{OAc})_{2}$ catalyzed $\mathrm{C}-\mathrm{H}$ hydroxylation of 2-benzoxazolyl- and 2-benzothiazolylarenes in the presence of $\mathrm{Na}_{2} \mathrm{~S}_{2} \mathrm{O}_{8}$ as oxidant in 1,4-dioxane (Scheme 37) [66]. They also showed that other

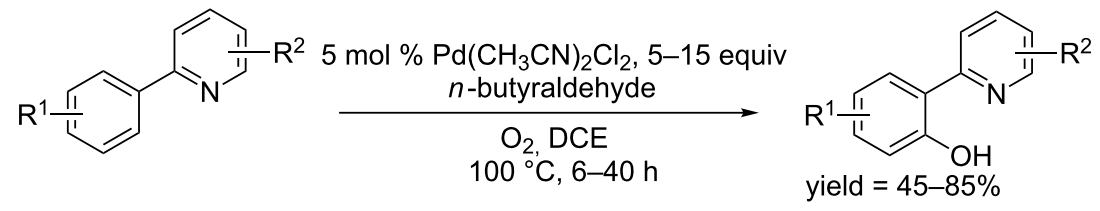

$\mathrm{R}^{1}=\mathrm{H}, \mathrm{Me}$, Et, $t$-Bu, $\mathrm{Ph}, \mathrm{OMe}, \mathrm{OBn}, \mathrm{MeCO}, \mathrm{F}, \mathrm{Br}, \mathrm{Cl}, \mathrm{CN}, \mathrm{CF}_{3}$; $\mathrm{R}^{2}=\mathrm{H}, \mathrm{Me}, t-\mathrm{Bu}, \mathrm{COOEt}, \mathrm{CN}, \mathrm{OMe}, \mathrm{NO}_{2}, \mathrm{MeCONH}, \mathrm{PhCONH}, \mathrm{MeCON}(\mathrm{Me})$

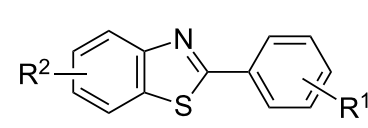

\section{$2 \mathrm{~mol} \% \mathrm{Pd}(\mathrm{OAc})_{2}$ 1 equiv $\mathrm{Phl}(\mathrm{OAc})_{2}$ \\ $\mathrm{AcOH}$ \\ $110^{\circ} \mathrm{C}, 3-8 \mathrm{~h}$}

$\mathrm{R}^{1}=\mathrm{H}, \mathrm{Me}$, OMe, $t-\mathrm{Bu}, \mathrm{OBu}, \mathrm{F}, \mathrm{Cl}, \mathrm{Br}, \mathrm{NO}_{2}$

$\mathrm{R}^{2}=\mathrm{H}, \mathrm{Me}, \mathrm{OMe}, \mathrm{CF}_{3}, \mathrm{Cl}$

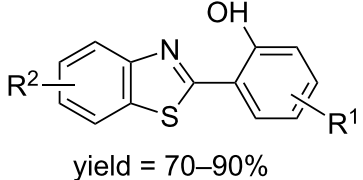

yield $=70-90 \%$

Scheme 35: $\mathrm{Pd}(\mathrm{OAc})_{2}$-catalyzed hydroxylation of benzothiazolylarenes.
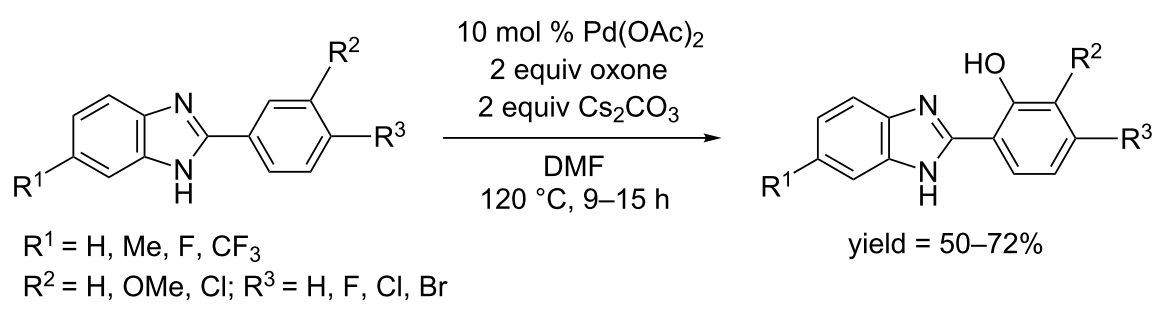

Scheme 36: $\mathrm{Pd}(\mathrm{OAc})_{2}$ catalyzed hydroxylation of benzimidazolylarenes. 


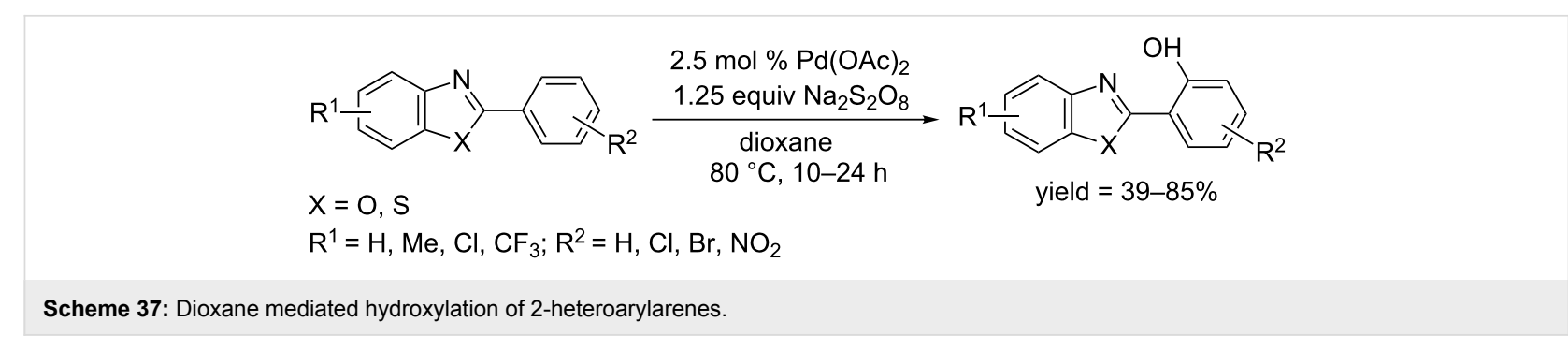

acyclic directing groups including azo, amide, anilide, carbamate and unsymmetrical urea, could also promote the orthohydroxylation of arenes. Remarkably, 1,4-dioxane not only served as the solvent, but also played an indispensable role in the oxidation of the palladium complex by generating hydroxyl radicals according to the proposed reaction mechanism.

In 2015, Jiao and co-workers employed an oxime methyl ester as directing group and achieved the hydroxylation of arenes [67]. The reaction used $\mathrm{Pd}(\mathrm{OAc})_{2}$ as catalyst, $\mathrm{PPh}_{3}$ or DEAD as ligand and oxone as oxidant, affording the corresponding phenols in gratifying yields (Scheme 38). Exploration of the substrate scope showed that both electron-rich and electrondeficient substrates were tolerated, although the latter of which provided lower yields. The functional group $\mathrm{R}^{2}$ could vary from alkyl to aryl group, enabling the synthesis of diverse phenols. Moreover, the hydroxylated oxime could be readily converted to $o$-acylphenol or $o$-aminomethylphenol.

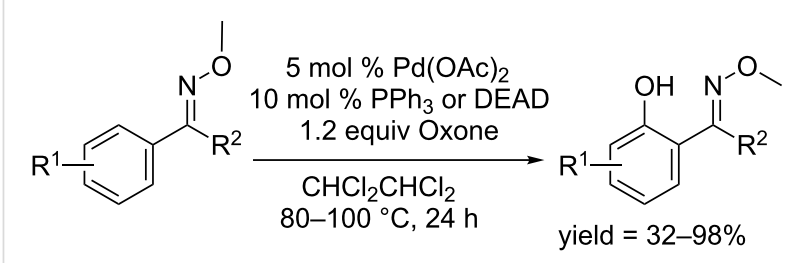

$\mathrm{R}^{1}=\mathrm{NO}_{2}, \mathrm{CF}_{3}, \mathrm{CN}, \mathrm{COOMe}, \mathrm{Ms}, \mathrm{COOH}, \mathrm{I}, \mathrm{Br}, \mathrm{Cl}, \mathrm{F}, t-\mathrm{Bu}$, $n-\mathrm{Bu}$, etc;

$\mathrm{R}^{2}=$ aryl, $\mathrm{H}, \mathrm{Me}, \mathrm{HOCH}_{2}, \mathrm{CH}_{2} \mathrm{CH}_{2} \mathrm{COOMe}$, etc

Scheme 38: Hydroxylation of oxime methyl ester.

In 2016, Sunoj and co-workers disclosed the first metahydroxylation of arenes using a tethered $-\mathrm{CN}$ directing group [68]. The conversion proceeded at $70{ }^{\circ} \mathrm{C}$ in hexafluoro-2propanol (HFIP) in the presence of $\mathrm{Pd}(\mathrm{OAc})_{2}, \mathrm{PhI}(\mathrm{TFA})_{2}$ and For-Gly-OH (Scheme 39). The substrate scope showed that both electron-donating and electron-withdrawing groups are tolerated, although electron-deficient arenes gave a bit lower yields. Notably, a replacement of PhI (TFA) 2 with $\mathrm{PhI}(\mathrm{OAc})_{2}$ afforded acyloxylated products. A careful mechanism investigation revealed that HFIP participated in the catalytic cycle before the activation of $\mathrm{C}-\mathrm{H}$ bond.

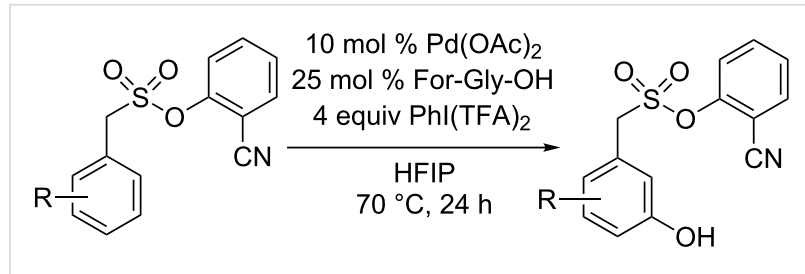

$\mathrm{R}=\mathrm{H}, \mathrm{Me}, \mathrm{F}, \mathrm{Cl}, \mathrm{Br}, \mathrm{iPr}, \mathrm{OPh}, \mathrm{F}, \mathrm{OCF}_{3} \quad$ yield $=51-77 \%$

Scheme 39: CN-directed meta-hydroxylation.

1.2.2.2 Carboxylic acid, ketone and their derivatives as directing groups: In 2009, the $\mathrm{Yu}$ group used $\mathrm{Pd}(\mathrm{OAc})_{2}$ and accomplished the direct ortho-hydroxylation of benzoic acid [69]. Their developed protocol used $10 \mathrm{~mol} \%$ of $\mathrm{Pd}(\mathrm{OAc})_{2}$ as catalyst, and the reaction was carried out under the atmosphere of molecular oxygen in the presence of KOAc and 1,4-benzoquinone (BQ) as additives (Scheme 40). The mechanism investigation indicated that molecular oxygen was involved in the product forming step rather than reoxidation of $\operatorname{Pd}(0)$ as the reaction couldn't proceed with a stoichiometric amount of $\mathrm{Pd}(\mathrm{OAc})_{2}$ under argon.

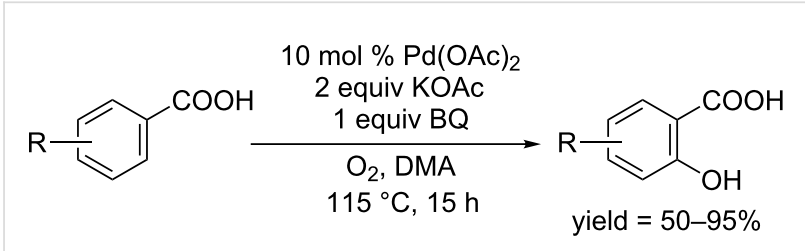

$\mathrm{R}=\mathrm{Cl}, \mathrm{F}, \mathrm{CN}, \mathrm{Me}, \mathrm{OMe}, \mathrm{NHCOMe}, \mathrm{COMe}, \mathrm{COPh}, \mathrm{CF}_{3}, \mathrm{NO}_{2}$

Scheme 40: $\mathrm{Pd}(\mathrm{OAc})_{2}$-catalyzed hydroxylation of benzoic acids.

In 2012, the Rao group and the Dong group simultaneously reported a palladium catalyzed ortho-hydroxylation of aryl ketones, and thus further broadened the directing groups of arene substrates [70,71]. Rao and co-workers found that both biaryl ketone and aryl alkyl ketones could be regioselectively hydroxylated in satisfying yields. The reaction proceeded in TFA/ TFAA in the presence of $\mathrm{Pd}(\mathrm{OAc})_{2}$ as catalyst and several type of oxidants including selectfluor, $\mathrm{PhI}(\mathrm{OAc})_{2}$ and $\mathrm{K}_{2} \mathrm{~S}_{2} \mathrm{O}_{8}$, respectively (Scheme 41). The regioselectivity was maintained in the presence of various functional groups. Further studies 
revealed that several functional groups such as esters, amides and sulfonamides could be added to the list of directing groups.

$$
\begin{aligned}
& \mathrm{R}^{1}=\mathrm{H}, \mathrm{F}, \mathrm{Cl}, \mathrm{Br}, \mathrm{Me}, \mathrm{OH}, \mathrm{OMe}, \mathrm{NHCOCF}_{3}, \mathrm{COOEt} \\
& \mathrm{R}^{2}=\text { aryl, alkyl groups }
\end{aligned}
$$

Scheme 41: $\mathrm{Pd}(\mathrm{OAc})_{2}$-catalyzed hydroxylation of biaryl or aryl alkyl ketones.

The Dong group reported a similar work and developed two types of reaction conditions for the hydroxylation of aryl alkyl ketones. The conditions using PhI(TFA) $)_{2}$ as oxidant and DCE as the solvent were milder and more selective, while the conditions using $\mathrm{K}_{2} \mathrm{~S}_{2} \mathrm{O}_{8}$ as oxidant and TFA as solvent were more reactive (Scheme 42). Interestingly, although the reaction gave the trifluoroacetates rather than phenols as products, phenols were readily obtained during the silica gel column chromatography.

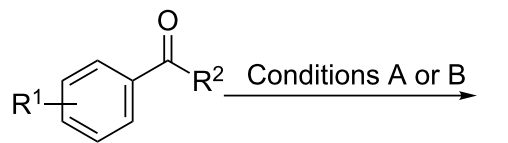<smiles>[R]C(=O)c1ccc[R4](O)c1</smiles>

$\mathrm{R}^{1}=\mathrm{Br}, \mathrm{Me}, \mathrm{MeO}$;

$\mathrm{R}^{2}=t-\mathrm{Bu}, \mathrm{Ph}, 4-\mathrm{Me}-\mathrm{Ph}, 4-\mathrm{NO}_{2}-\mathrm{Ph}, 4-\mathrm{MeO}-\mathrm{Ph}$

Conditions $A$ :

5 mol \% Pd(TFA $)_{2} ; 2$ equiv Phl(TFA $)_{2}$; DCE; $80{ }^{\circ} \mathrm{C}, 1.5-12 \mathrm{~h}$

Conditions $B$ :

$5 \mathrm{~mol} \% \mathrm{Pd}(\mathrm{OAc})_{2} ; 2$ equiv $\mathrm{K}_{2} \mathrm{~S}_{2} \mathrm{O}_{8} ;$ TFA; $50{ }^{\circ} \mathrm{C}, 1.5-10 \mathrm{~h}$

Scheme 42: $\mathrm{Pd}(\mathrm{OAc})_{2}$ and $\mathrm{Pd}(\mathrm{TFA})_{2}$ catalyzed hydroxylation of aryl ketones.

In 2013, an acid-free procedure for the regioselective hydroxylation of aryl ketones was reported by Kwong and co-workers
[72]. They used $\mathrm{Pd}(\mathrm{OAc})_{2}$ as catalyst and $\mathrm{PhI}(\mathrm{OTFA})_{2}$ as oxidant, affording phenols in good yields in DCE at $80{ }^{\circ} \mathrm{C}$ (Scheme 43). The reaction system showed great efficiency as most reactions accomplished within 2 hours. Moreover, variable alkyl groups $\left(\mathrm{R}^{2}\right)$ including cyclohexyl, cyclopropyl, butyl and tert-butyl, diversified the structure of the produced phenols.

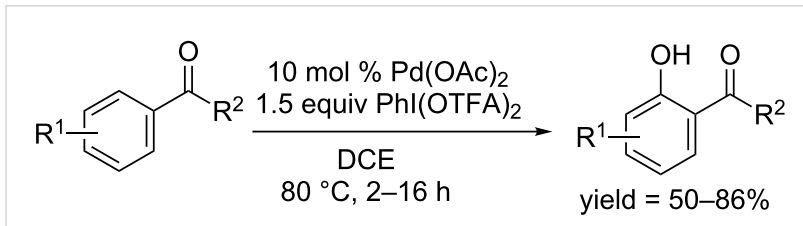

$\mathrm{R}^{1}=\mathrm{H}, \mathrm{OMe}, \mathrm{F}, \mathrm{Cl}, \mathrm{Br}$

$\mathrm{R}^{2}=$ aryl, cyclohexyl, cyclopropyl, Me, $n-\mathrm{Bu}, t-\mathrm{Bu}$, etc

Scheme 43: $\mathrm{Pd}(\mathrm{OAc})_{2}$ catalyzed hydroxylation of aryl ketones.

In 2013, Yang and co-workers reported the first phosphonatedirected hydroxylation of arenes for the synthesis of 2'-phosphorylbiphenyl-2-ol [73]. The reaction was catalyzed by $\mathrm{Pd}(\mathrm{TFA})_{2}$ in the presence of $\mathrm{PhI}(\mathrm{OAc})_{2}$ as oxidant (Scheme 44). Screening for directing groups found a series of dialkyl and diaryl phosphonates were compatible with the hydroxylation condtions, while monoalkyl phosphonate gave the phosphoryl lactone as product. Exploration of substrate scope showed that both electron-donating groups (such as $\mathrm{Me}$, $\mathrm{OMe}$ ) and electron-withdrawing groups (such as $\mathrm{F}, \mathrm{Cl}, \mathrm{Br}, \mathrm{CF}_{3}$ ) are tolerable.

1.2.2.3 Phenol as directing groups: In 2016, the Zhang and Fan group described the first phenolic moiety directed hydroxylation. $\mathrm{Pd}(\mathrm{OAc})_{2}$ catalyzed hydroxylation of [1, 'biphenyl]-2-ols using TBHP as oxidant in acetonitrile (Scheme 45) [74]. The reaction predominantly afforded biphenols as product, rather than dibenzofurans through an intramolecular transformation. Similar with Sun's work in 2015 [62], this conversion was also considered to proceed through an oxidation of $\mathrm{Pd}(\mathrm{II})$ to $\mathrm{Pd}(\mathrm{IV})$ by radical $\mathrm{HO} \cdot$. Under the optimum conditions, a broad scope of functional groups was well tolerated.

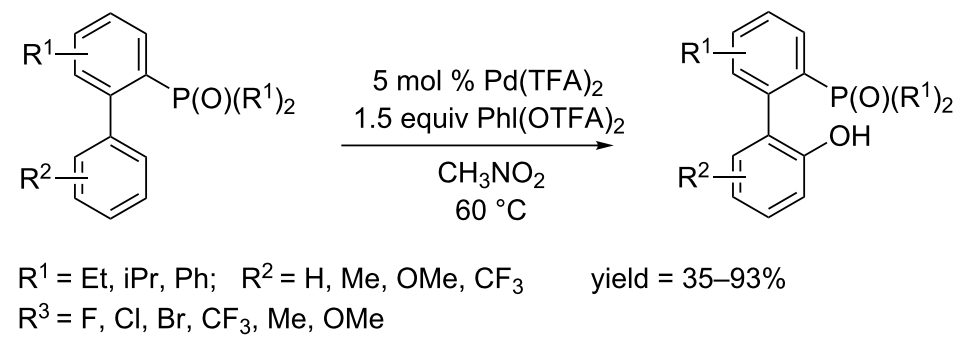

Scheme 44: $\operatorname{Pd}(\mathrm{TFA})_{2}$-catalyzed hydroxylation of aryl phosphonates. 


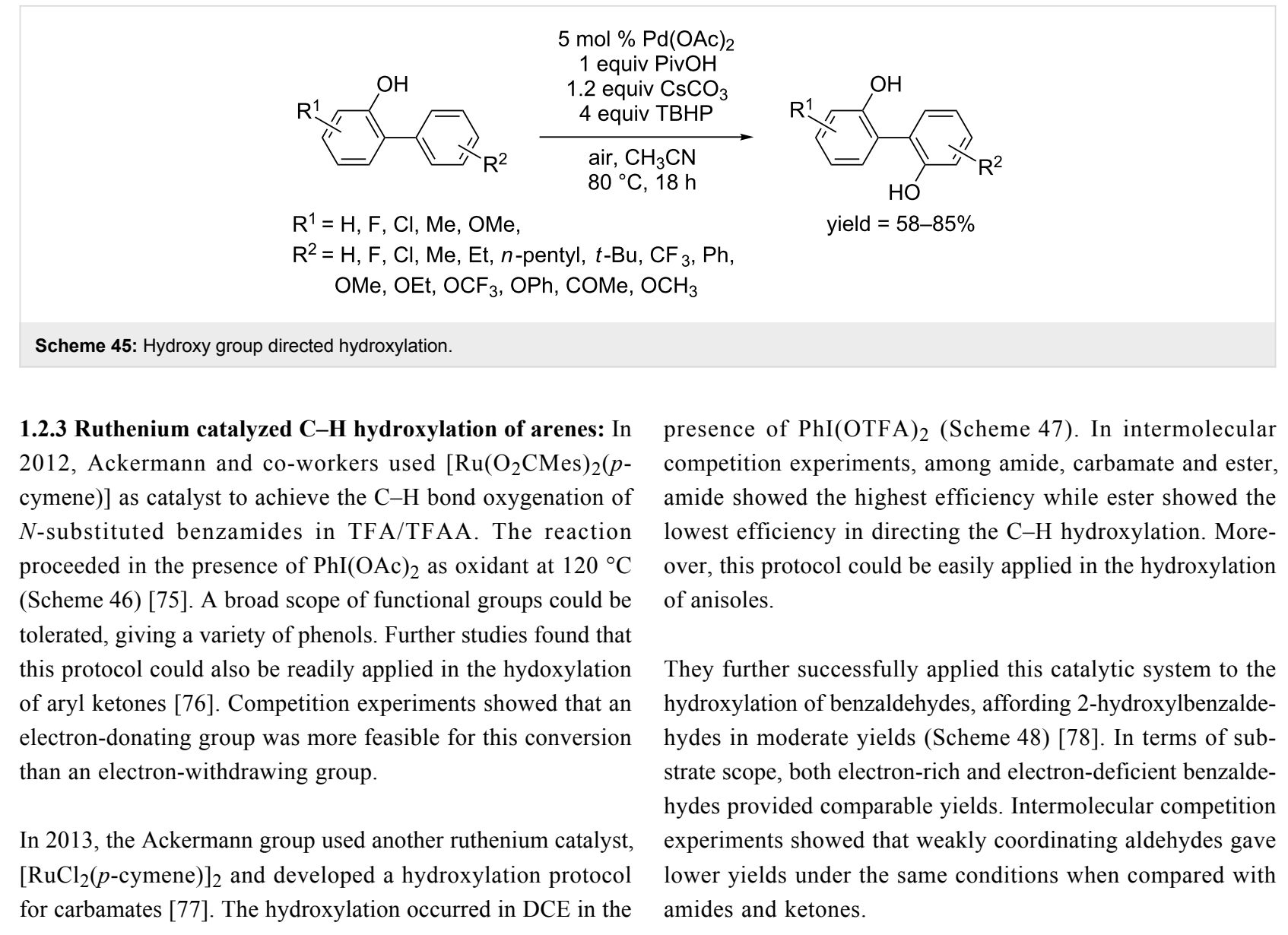<smiles>[R12]NC(=O)c1cc[R]cc1O</smiles>

$\mathrm{R}^{1}=\mathrm{H} ; \mathrm{R}^{2}=\mathrm{iPr}$, Et, Me, etc.; yield $=55-96 \%$

$\mathrm{R}^{2}=\mathrm{iPr}, \mathrm{R}^{1}=\mathrm{F}, \mathrm{Cl}, \mathrm{Br}, \mathrm{I}, \mathrm{Me}, \mathrm{Ph}, \mathrm{OMe}, \mathrm{COOMe}, \mathrm{CF}_{3}, \mathrm{NO}_{2} ;$ yield $=42-92 \%$

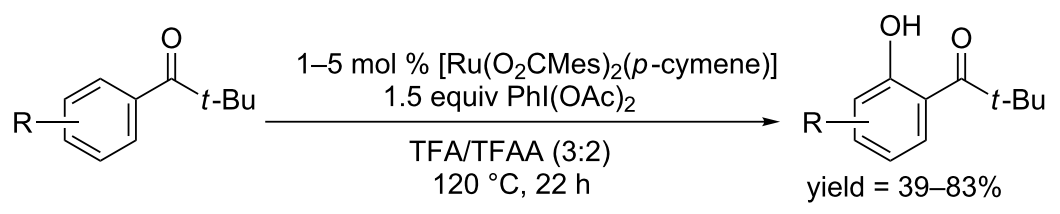

$\mathrm{R}=\mathrm{F}, \mathrm{Cl}, \mathrm{Br}, \mathrm{I}, \mathrm{Me}, \mathrm{CF}_{3}, \mathrm{Ph}, \mathrm{OMe}$

Scheme 46: $\left[\mathrm{Ru}\left(\mathrm{O}_{2} \mathrm{CMes}\right)_{2}(p\right.$-cymene $\left.)\right]$ catalyzed hydroxylation of benzamides and aryl ketones.

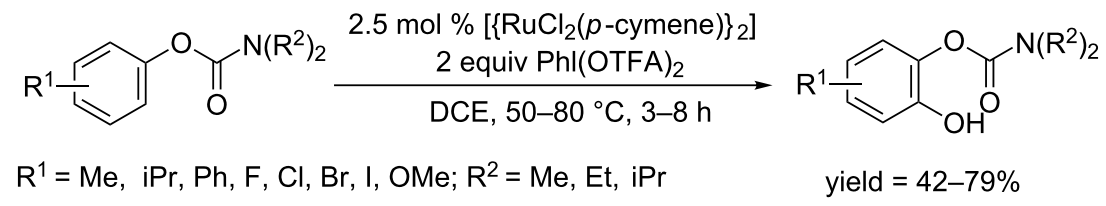



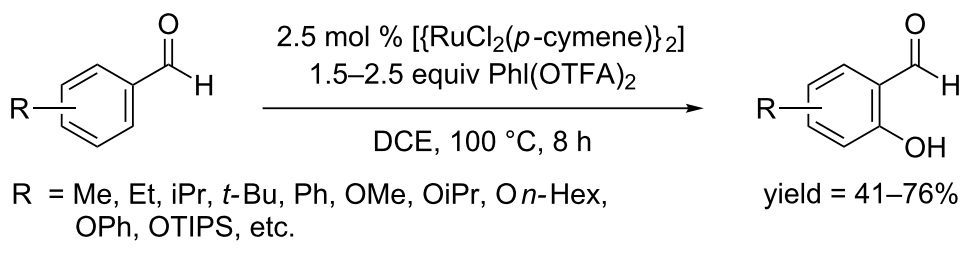

yield $=41-76 \%$

Scheme 48: $\left[\mathrm{RuCl}_{2}(p \text {-cymene })\right]_{2}$ catalyzed hydroxylation of benzaldehydes.

The Rao group developed a catalytic system of $\left[\mathrm{RuCl}_{2}(p-\right.$ cymene) $]_{2}$ and $\mathrm{K}_{2} \mathrm{~S}_{2} \mathrm{O}_{8}$ in TFA/TFAA, which promoted the hydroxylation of ethyl benzoates, benzamides and carbamates (Scheme 49). They reported the first ortho-hydroxylation of ethyl benzoates in 2012 [79]. Both electron-rich and electrondeficient ethyl benzoates were readily converted to the corresponding hydroxylated products. In 2013, they further applied this protocol to the hydroxylation of $N$-aryl-2,6-difluorobenzamides [80]. The ortho-, meta-, and para-substituent groups, as well as the electron-withdrawing groups (such as halides, $\mathrm{CF}_{3}$, ester, etc.) and electron-donating functional groups (such as methyl, methoxy, etc) were well tolerated. In 2014, the tolerance of this protocol for carbamates and esters was studied [81]. Carbamates were compatible with this protocol, however, esters gave lower yields. A replacement of $\left[\mathrm{RuCl}_{2} \text { (p-cymene) }\right]_{2}$ with $\mathrm{Pd}(\mathrm{OAc})_{2}$ gave the hydroxylated carbamates at room temperature although yields were lowered.

In 2016, the Rao group described a regioselective hydroxylation protocol for benzanilides [82]. Two phenyl rings of $\mathrm{N}$-alkylbenzanilides could be differentiated in the orthohydroxylation by choosing different catalysts (Scheme 50). In the catalytic system consisting of $\left[\mathrm{RuCl}_{2}(p \text {-cymene })\right]_{2}$ and $\mathrm{K}_{2} \mathrm{~S}_{2} \mathrm{O}_{8}$, the $\mathrm{C}-\mathrm{H}$ hydroxylation occurred at the position ortho to the carbonyl group. Different regioselective hydroxylation was observed when $\left[\mathrm{RuCl}_{2}(p \text {-cymene })\right]_{2}$ was replaced with $\mathrm{Pd}(\mathrm{OAc})_{2}$, by which $\mathrm{C}-\mathrm{H}$ hydroxylation predominantly occurred at the position ortho to the aniline group. A mechanism investigation showed that the different regioselectivity was controlled by steric and electronic effects.

In 2015, Hong and co-workers developed a $\mathrm{C}-\mathrm{H}$ hydroxylation protocol for flavones; their work is of importance because the hydroxy group has a great impact on the biological activities of 5-hydroxyflavonids [83]. Starting from $\left[\mathrm{RuCl}_{2}(p \text {-cymene) }]_{2}\right.$, $\mathrm{Ag}_{2} \mathrm{CO}_{3}$ and $\mathrm{CF}_{3} \mathrm{COOH}$, they prepared a ruthenium complex, which could achieve the regioselective hydroxylation of flavones at $80{ }^{\circ} \mathrm{C}$ in TFA/TFAA in the presence of $\mathrm{PhI}(\mathrm{TFA})_{2}$ as oxidant (Scheme 51).

1.2.4 Vanadium mediated $\mathbf{C}-\mathbf{H}$ hydroxylation of arenes: In 2012, Mizuno employed divanadium-substituted phosphotungstate, and accomplished the direct hydroxylation of structurally simple arenes to phenols in the presence of $\mathrm{H}_{2} \mathrm{O}_{2}$ [84].<smiles>[R][X]1cccc(C(=O)OCC)c1</smiles><smiles>[R]c1ccc(NC(=O)c2c(F)cccc2F)cc1</smiles>

$\mathrm{R}=\mathrm{F}, \mathrm{Cl}, \mathrm{Br}, \mathrm{CF}_{3}, \mathrm{Me}, \mathrm{OMe}, \mathrm{OE}$
$2.5 \mathrm{~mol} \%\left[\left\{\mathrm{RuCl}_{2}(p \text {-cymene })\right\}_{2}\right]$ 1.1 equiv $\mathrm{K}_{2} \mathrm{~S}_{2} \mathrm{O}_{8}$

TFA/TFAA (7:3)

$90{ }^{\circ} \mathrm{C}, 11 \mathrm{~h}$

$\mathrm{Me}, \mathrm{COOMe}$

$2.5 \mathrm{~mol} \%\left[\left\{\mathrm{RuCl}_{2}(p \text {-cymene })\right\}_{2}\right]$ 2 equiv $\mathrm{K}_{2} \mathrm{~S}_{2} \mathrm{O}_{8}$

TFA/TFAA (1:1) $80^{\circ} \mathrm{C}, 12 \mathrm{~h}$<smiles>[R]c1ccc(C(=O)OCC)c(O)c1</smiles>

yield $=7-92 \%$<smiles>[R][R]1ccc(OC(=O)N(C)C)cc1</smiles>

$2.5 \mathrm{~mol} \%\left[\left\{\mathrm{RuCl}_{2}(p \text {-cymene })\right\}_{2}\right]$ 2 equiv $\mathrm{K}_{2} \mathrm{~S}_{2} \mathrm{O}_{8}$

TFA/TFAA (1:1)

$80^{\circ} \mathrm{C}, 1-3 \mathrm{~h}$<smiles>[R][X]1=CC=C(O)C(O)=CC1NC(=O)c1c(F)cccc1F</smiles>
yield $=40-90 \%$<smiles>[R][14c]1ccc(OC(=O)N(C)C)c(O)c1</smiles>

$\mathrm{R}=\mathrm{F}, \mathrm{Cl}, \mathrm{Br}, \mathrm{CF}_{3}, \mathrm{CHO}, \mathrm{MeCO}, \mathrm{Me}, t-\mathrm{Bu}, \mathrm{OMe}, \mathrm{Ph}, \mathrm{NO}_{2}$, etc 
<smiles>[R][R]1ccc(C(=O)N([R])c2cccc([R])c2)cc1</smiles>

$\mathrm{R}^{1}=\mathrm{H}, \mathrm{Me}, \mathrm{OMe}, \mathrm{F}, \mathrm{Cl}, \mathrm{Br}, \mathrm{CF}_{3}, \mathrm{NO}_{2}$; yield $=61-95 \%$ $\mathrm{R}^{2}=\mathrm{H}, \mathrm{F}, \mathrm{Cl}, \mathrm{Br}, \mathrm{Me}, \mathrm{COOEt}, \mathrm{CF}_{3}, \mathrm{NO}_{2}$; $\mathrm{R}^{3}=\mathrm{Me}, \mathrm{Et}, \mathrm{Bn}$<smiles>[R][R]1ccc(C(=O)N([R])c2cccc([R])c2)cc1</smiles>

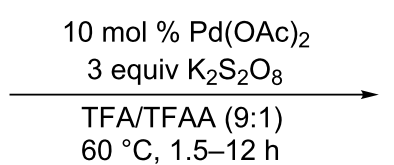<smiles>[R][Y]1cccc(C(=O)N([R])c2ccccc2O)c1</smiles>

$\mathrm{R}^{1}=\mathrm{H}, \mathrm{Me}, \mathrm{OMe}, \mathrm{F}, \mathrm{Cl}, \mathrm{Br}, \mathrm{I}, \mathrm{CF}_{3}, \mathrm{NO}_{2}$, cyclohexyl; yield $=46-94 \%$ $\mathrm{R}^{2}=\mathrm{H}, \mathrm{F}, \mathrm{Cl}, \mathrm{Br}, \mathrm{Me}, \mathrm{OMe}$; $\mathrm{R}^{3}=\mathrm{Me}, \mathrm{Et}, \mathrm{Bn}$

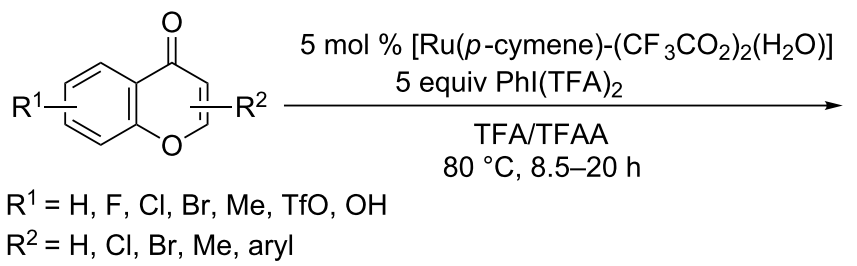<smiles>[R]c1cc(=O)c2c(O)cccc2o1</smiles>

yield $=44-87 \%$

Scheme 51: Ruthenium-complex-catalyzed hydroxylation of flavones.

The reaction occurred at $60{ }^{\circ} \mathrm{C}$ in $\mathrm{CH}_{3} \mathrm{CN} / t$-BuOH (1:1) and afforded phenols in good to excellent yields (Scheme 52). In most cases, para-hydroxylation predominantly occurred, showing good regioselectivity. This protocol is suitable for hydroxylation of simple arenes as no particular directing group was required.

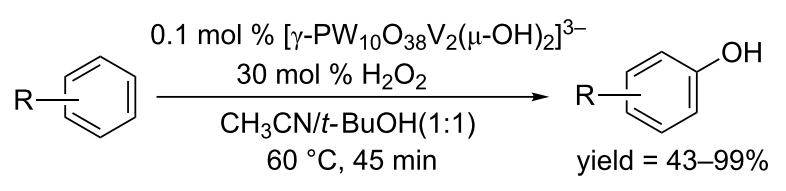

$\mathrm{R}=\mathrm{Me}, \mathrm{Et}, \mathrm{iPr}, \mathrm{t}-\mathrm{Bu}, \mathrm{Bn}, \mathrm{OH}, \mathrm{OMe}$

Scheme 52: Vanadium-catalyzed hydroxylation of arenes.

In 2015 , the Huang group prepared a type of vanadium catalysts supported on $\mathrm{N}$-doped carbon materials (VOSiW), which showed catalytic activity to convert electron-deficient arenes to phenols, however, the yields and selectivity were not very satisfying (Scheme 53) [85].

$$
\underset{\substack{\mathrm{O}_{2}, \mathrm{AcOH} / \mathrm{H}_{2} \mathrm{O} \\ 105^{\circ} \mathrm{C}, 11 \mathrm{~h}}}{\frac{1.3 \mathrm{~mol} \% \text { VOSiW }}{1.5 \text { equiv ascorbic acid }}}
$$

Scheme 53: VOSiW-catalyzed hydroxylation of arenes.

\section{Transition-metal-catalyzed synthesis of aryl thiols}

Traditional methods for the synthesis of aryl thiols include the Leukart thiophenol synthesis [86], the Newman-Kart reaction $[87,88]$ and the Schonberg reaction [89]. These methods often require multiple steps and/or harsh conditions. The reduction of phenylsulfonic chloride and disulfide can also afford aryl thiols, but the preparation of these specific precursors often needs laborious work.

The direct nucleophilic substitution of aryl halides with sodium alkyl sulfate was considered a simple strategy for the synthesis of aryl thiols [90-92]. However, these non-catalyzed conver- 
sions require excess amounts of sodium alkyl sulfate, high temperatures and toxic organic solvents, and thus limited the substrate scope and wide application.

As mentioned above, the development of transition-metal-catalyzed $\mathrm{C}-\mathrm{O}$ coupling reaction stimulated the emergence of new protocols for phenol synthesis. However, a rapid development of new methods for aryl thiol preparation was not observed. There may be two reasons which block the development of synthetic methods for aryl thiols: (1) Traditionally, sulfur was considered poisonous to transition metal catalysts $[93,94]$ (2) aryl thiols are very reactive forming intermolecular or intramolecular sulfide and disulfide compounds, so that it is difficult to isolate aryl thiols as final product. For example, many reactions use aryl thiols as active intermediates to form benzothiazoles from aryl halides $[95,96]$.

The first report of a transition-metal-catalyzed synthesis of aryl thiol appeared in 1985 [97], but there was no report until this century. Most of the known methods involve a two-step strategy. More recently, a few examples of single-step syntheses of aryl thiols have been reported.

\subsection{Two step strategy for the mercaptolization of aryl halides}

In 1985, Tiecco and co-workers succeeded in a Nickel catalyzed thiolation of aryl iodides with thiourea in DMF. Aryl iodides firstly reacted with thiourea in the presence of bis(triethylphosphine)nickel(II) chloride and sodium cyanoborohydride as catalyst precusor, and afforded aryl isothiuronium iodide, which could be further converted to aryl thiol through an alkali hydrolysis (Scheme 54). Compared with non- catalyzed methods, this protocol has several advantages, such as low reaction temperature $\left(60{ }^{\circ} \mathrm{C}\right)$, broader substrate scope including $\mathrm{OMe}$ and $\mathrm{NH}_{2}$-substituted iodobenzenes, and higher yields up to $98 \%$ (GC determined). In 2010, the Qi group reported a similar protocol to achieve the coupling of aryl iodides and thiourea by $\mathrm{CuI} / \mathrm{L}$-proline-catalyzed reaction in the presence of $\mathrm{Cs}_{2} \mathrm{CO}_{3}$ as base in DMSO [98].

In 2004, the Itoh group demonstrated that $\mathrm{Pd}_{2}(\mathrm{dba})_{3} /$ Xantphos (L14) could catalyze the coupling of aryl halides and aryl or alkyl thiols in the presence of $\mathrm{iPr}_{2} \mathrm{Net}$ (Scheme 55) [99]. They showed that the coupled products, aryl pyridinethyl thioether and aryl alkyloxycarbonylethyl thioether, could be converted to aryl thiols under specified conditions, respectively.

In 2010, the Hartwig group developed a $\mathrm{Pd}(\mathrm{OAc})_{2} / \mathrm{CyPF}-t-\mathrm{Bu}$ (L15) catalyzed coupling of aryl bromides and TIPS-SH, where the reaction was carried out in the presence of lithium bis(trimethylsilyl)amide (LiHMDS) in toluene at $110^{\circ} \mathrm{C}$ (Scheme 56) [100]. The coupled product of 1-bromonaphthalene and TIPSSH could be readily converted to 1-thionaphthol when treated with TBAF.

In 2011, the Fu and Guo group reported that $\mathrm{Pd}(\mathrm{OAc})_{2} / \mathrm{X}-\mathrm{Phos}$ (L16) and $\mathrm{Pd}_{2}(\mathrm{dba})_{3} / \mathrm{X}$-Phos-catalyzed thiolation of aryl bromide and chloride using sodium thiosulfate as thiol source [101]. The coupling reaction proceeded in water in the presence of $\mathrm{Cs}_{2} \mathrm{CO}_{3}$, and first gave aryl thiosulfate, which was further reduced by $\mathrm{Zn} / \mathrm{HCl}$ in the following step to provide aryl thiols (Scheme 57). Their developed protocol could convert aryl bromide, aryl chloride and aryl trifluoromethanesulfonate to the corresponding aryl thiols in moderate to excellent yields.

$$
\begin{array}{ll}
\text { 1) } 2 \mathrm{~mol} \% \mathrm{NiCl}_{2}\left(\mathrm{PEt}_{3}\right)_{2} \\
0.03 \text { equiv } \mathrm{NaBH}_{3} \mathrm{CN}
\end{array}
$$

Scheme 54: Synthesis of aryl thiols using thiourea as thiol source.

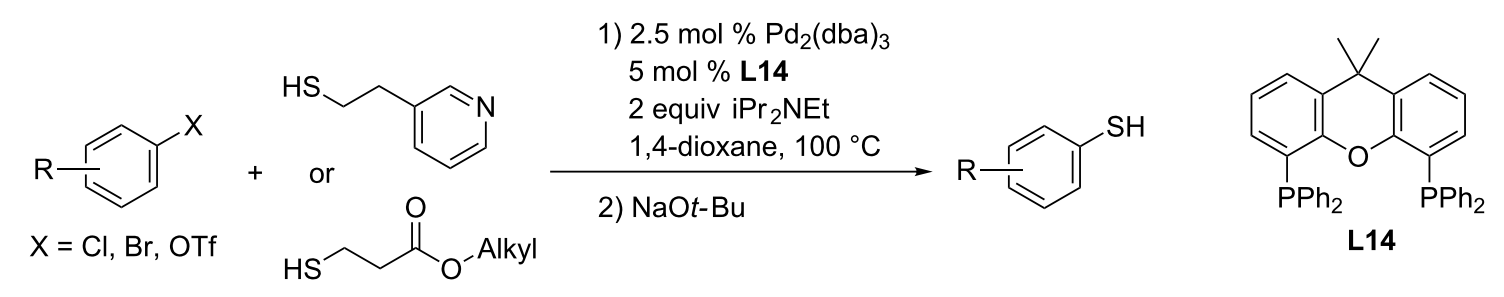




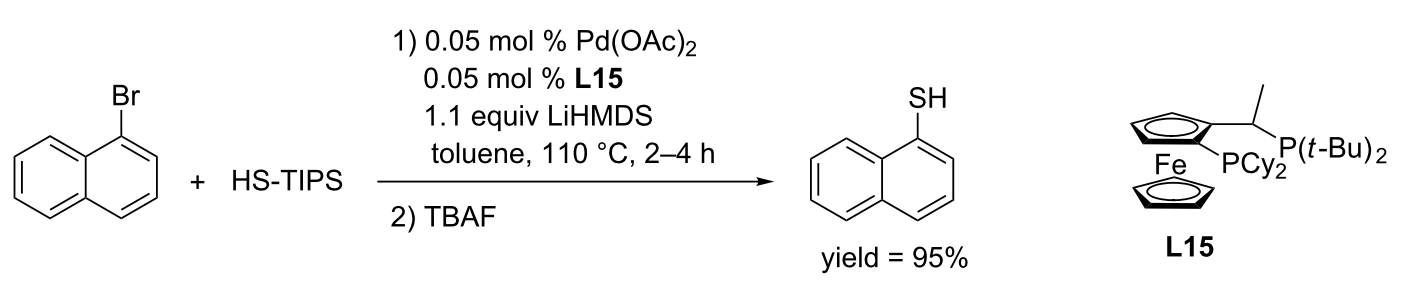

Scheme 56: Synthesis of 1-thionaphthol using HS-TIPS as thiol source.

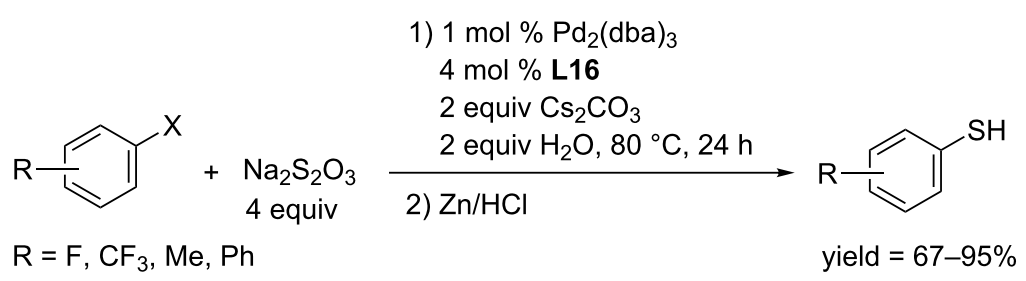<smiles>CC(C)c1cc(C(F)(F)F)cc(-c2ccccc2C(F)(F)F)c1-c1ccccc1</smiles>

Scheme 57: Synthesis of aryl thiols using sodium thiosulfate as thiol source.

In comparison to palladium catalysts, copper catalyzed thiolation of aryl halides have been extensively studied. In 2006, the Sawada group reported that aryl iodides could couple with thiobenzoic acid in the presence of a copper catalyst and 1,10phenanthroline (L17), affording $S$-aryl thiocarboxylates in excellent yields [102]. The coupled product was converted to aryl thiols in quantitative yield when treated with $\mathrm{K}_{2} \mathrm{CO}_{3}$ (Scheme 58).
In 2009, Ma and co-workers unprecedentedly used simple and economical sulfur powder as thiol source and developed an effective method for the synthesis of aryl thiols. They demonstrated that simple sulfur powder could couple with aryl iodides at $90{ }^{\circ} \mathrm{C}$ in the presence of $\mathrm{CuI}$ as catalyst to afford biaryl disulfides and polysulfides, which could be further converted to aryl thiols through a followed reduction using $\mathrm{NaBH}_{4}$ or $\mathrm{PPh}_{3}$ (Scheme 59) [103]. A wide range of functional groups includ-

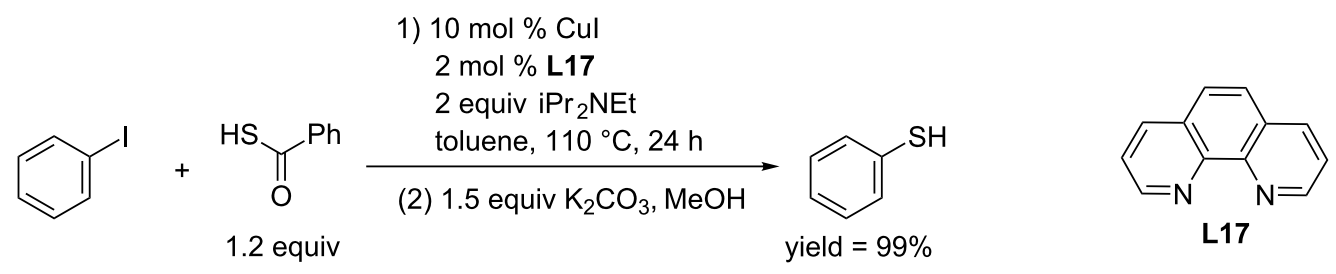

Scheme 58: Synthesis of thiophenol using thiobenzoic acid as thiol source.

(1) $10 \mathrm{~mol} \% \mathrm{Cul}$

2 equiv $\mathrm{K}_{2} \mathrm{CO}_{3}$

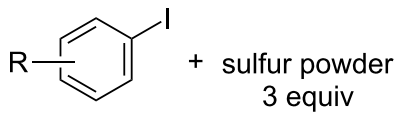

DMF, $90{ }^{\circ} \mathrm{C}, 4-12 \mathrm{~h}$

$\mathrm{R}=\mathrm{F}, \mathrm{Br}, \mathrm{COOH}, \mathrm{NHAc}, \mathrm{NO}_{2}, \mathrm{Me}, \mathrm{OMe}, \mathrm{CH}_{2} \mathrm{OH}$,

(2) 3 equiv $\mathrm{NaBH}_{4}$ or $\mathrm{Ph}_{3} \mathrm{P}$<smiles>Sc1cc[R]cc1</smiles>

yield $=82-92 \%$

$\mathrm{COOH}, \mathrm{CF}_{3}$, $\mathrm{COMe}$, etc 
ing methoxy, hydroxy, acyl, carboxy, amide, bromo and trifluoromethyl were tolerated in this process. They also showed the application of the developed protocol in the synthesis of aryl alkyl sulfides via a "one-pot reaction".

In 2011, the Xu and Feng group applied CuI-nanoparticles to synthesize aryl thiols through a coupling reaction of aryl halides and sulfur powder followed by a reduction using $\mathrm{Zn} / \mathrm{HCl}$ (Scheme 60) [47]. The reaction proceeded in water in the presence of $n-\mathrm{Bu}_{4} \mathrm{NOH}$, making the reaction green. Both aryl iodides and activated aryl bromides could give moderate to excellent yields.

\subsection{Single step strategy for the mercaptolization of aryl halides}

Transition-metal-catalyzed methods provides various thiolation protocols, which allow an access to aryl thiols. However, all these methods described above require two steps, causing more labor both in the laboratory and industry. In this context, one step conversions were desirable.
In 2013, in the study of the synthesis of (Z)-3-arylthioacrylic acids and thiochromenones, Lee and co-workers found that $89 \%$ yield of thiophenol could be directly obtained by $\mathrm{Pd}\left(\mathrm{PPh}_{3}\right)_{2} \mathrm{Cl}_{2} /$ dppb (L18) catalyzed coupling reaction of iodobenzene and $\mathrm{Na}_{2} \mathrm{~S} \cdot 5 \mathrm{H}_{2} \mathrm{O}$ in the presence of DBU (Scheme 61) [104].

In 2015, on the basis of a successful application of ethylene glycol in a phenol synthesis [39], the Chae group developed a single-step protocol for the direct synthesis of aryl thiols. The protocol employed $\mathrm{CuSO}_{4} \cdot 5 \mathrm{H}_{2} \mathrm{O}$ as the catalyst and $\mathrm{KOH}$ or $\mathrm{Cs}_{2} \mathrm{CO}_{3}$ as bases, and could convert aryl iodides, and aryl bromides bearing electron-withdrawing groups to the corresponding aryl thiols in good to excellent yields (Scheme 62) [105]. During the reaction, neither disulfide nor sulfide was formed. A simple investigation showed that aryl halides may first couple with 1,2-ethanedithiol and the coupled product was converted in situ to aryl thiols through $\mathrm{C}-\mathrm{S}$ bond cleavage by an intramolecular nucleophilic substitution. The protocol tolerated a broad range of functional groups such as amino, hydroxy, trifluoromethyl, ester, carboxy and formyl groups.

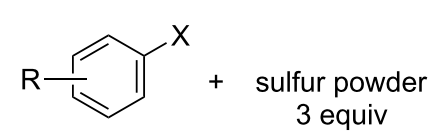

$\mathrm{X}=\mathrm{I}, \mathrm{Br}$

$\mathrm{R}=\mathrm{Cl}, \mathrm{COOH}, \mathrm{Me}, \mathrm{OMe}, \mathrm{NH}_{2}$
1) $1.5 \mathrm{~mol} \%$ Cul nanoparticles 3 equiv $n-\mathrm{Bu}_{4} \mathrm{NOH}$ $\mathrm{H}_{2} \mathrm{O}, 25-80{ }^{\circ} \mathrm{C}, 24-48 \mathrm{~h}$

2) $\mathrm{Zn} / \mathrm{HCl}$<smiles>[Y]=CC=CCCCCC</smiles>

yield $=84-94 \%$

Scheme 60: Cul-nanoparticles catalyzed synthesis of aryl thiols.

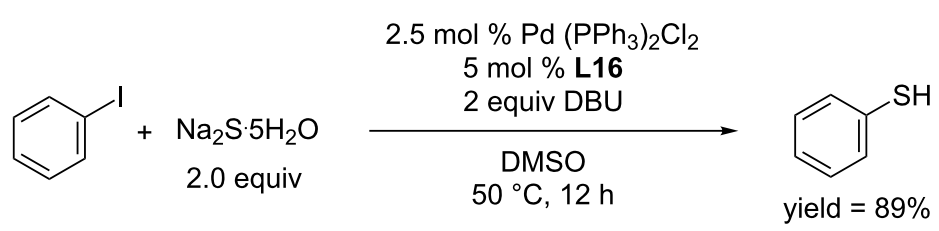

$50^{\circ} \mathrm{C}, 12 \mathrm{~h}$

$$
\text { yield }=89 \%
$$

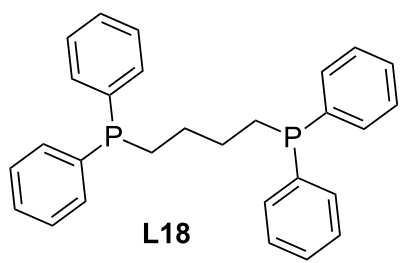

L18<smiles>[R]c1ccc([X])cc1</smiles>

$\mathrm{X}=\mathrm{I}, \mathrm{Br}, \mathrm{Cl}$

$\mathrm{R}=\mathrm{Br}, \mathrm{Cl}, \mathrm{Me}, \mathrm{OMe}, \mathrm{OH}, \mathrm{NH}_{2}, \mathrm{Ph}, \mathrm{CN}, \mathrm{CHO}, \mathrm{COOH}, \mathrm{CF}_{3}, \mathrm{NO}_{2}$

\section{$5 \mathrm{~mol} \% \mathrm{CuSO}_{4} \cdot 5 \mathrm{H}_{2} \mathrm{O}$}

5 equiv $\mathrm{KOH}$ or $\mathrm{Cs}_{2} \mathrm{CO}_{3}$

DMSO/ $\mathrm{H}_{2} \mathrm{O}(10: 1)$

$60-110^{\circ} \mathrm{C}, 20 \mathrm{~h}$<smiles>[R][X]1ccc(S)cc1</smiles>

yield $=81-99 \%$ 
As described above, although it seems more difficult to develop an effective protocol for the synthesis of aryl thiols than for phenols, some pioneering work showed great improvements in this field. On the other hand, to the best of our knowledge, there is no report on the synthesis of aryl thiols through $\mathrm{C}-\mathrm{H}$ activation.

\section{Conclusion}

In conclusion, tremendous progress has been made towards the synthesis of phenols and aryl thiols through transition-metalcatalyzed coupling reactions. However, there is still much space for improvement, and therefore the research in this field will be continued. In terms of the synthesis of phenols, since transitionmetal-catalyzed hydroxylations of aryl halides have been well established, further efforts should be made in the $\mathrm{C}-\mathrm{H}$ hydroxylation of arenes, allowing more types of arenes to be directly hydroxylated affording phenols. On the other hand, since ortho-hydroxylation has been extensively studied, remote direction of $\mathrm{C}-\mathrm{H}$ hydroxylation can be another orientation for further developments. In terms of the synthesis of aryl thiols, the direct synthesis of aryl thiols using simple thiol sources and $\mathrm{C}-\mathrm{H}$ mercaptolization of arenes would be desired as future direction.

\section{Acknowledgements}

This work was supported by Dalian University of Technology Fundamental Research Fund (DUT15RC(3)043) and Natural Science Foundation of Liaoning Province, China (No. 2015020745).

\section{References}

1. Rappoport, Z., Ed. The Chemistry of Phenols, 2nd ed.; PATAI'S Chemistry of Functional Groups; John Wiley \& Sons Ltd.: Chichester, U.K., 2003. doi:10.1002/0470857277

2. Roughley, S. D.; Jordan, A. M. J. Med. Chem. 2011, 54, 3451-3479. doi:10.1021/jm200187y

3. Hoyle, C. E.; Lowe, A. B.; Bowman, C. N. Chem. Soc. Rev. 2010, 39, 1355-1387. doi:10.1039/b901979k

4. Hand, C. E.; Honek, J. F. J. Nat. Prod. 2005, 68, 293-308. doi:10.1021/np049685x

5. Stambuli, J. P. Transition Metal-Catalyzed Formation of C-O and C-S Bonds. New Trends in Cross-Coupling: Theory and Applications; RSC Catalysis Series, Vol. 21; Royal Society of Chemistry, 2015; pp 254-275. doi:10.1039/9781782620259-00254

6. Eichman, C. C.; Stambuli, J. P. Molecules 2011, 16, 590-608. doi:10.3390/molecules16010590

7. Tlili, A.; Taillefer, M. Ullmann Condensation Today: Arylation of Alcohols and Thiols with Aryl Halides. In Copper Mediated Cross-Coupling Reactions; Evano, G.; Blanchard, N., Eds.; John Wiley \& Sons, Inc.: New Jersey, 2014; pp 41-91.

8. Song, G.; Wang, F.; Li, X. Chem. Soc. Rev. 2012, 41, 3651-3678. doi:10.1039/c2cs15281a

9. Liu, B.; Shi, B.-F. Tetrahedron Lett. 2015, 56, 15-22. doi:10.1016/j.tetlet.2014.11.039
10. Alonso, D. A.; Nájera, C.; Pastor, I. M.; Yus, M. Chem. - Eur. J. 2010, 16, 5274-5284. doi:10.1002/chem.201000470

11. Boswell, M. C.; Dickson, J. V. J. Am. Chem. Soc. 1918, 40, 1786-1793. doi:10.1021/ja02245a005

12. Dakin, H. D. Am. Chem. J. 1909, 42, 477-498.

13. Dakin, H. D. Org. Synth. 1923, 3, 28-32. doi:10.15227/orgsyn.003.0028

14. Hanson, P.; Rowell, S. C.; Walton, P. H.; Timms, A. W. Org. Biomol. Chem. 2004, 2, 1838-1855. doi:10.1039/b404699d

15. Ullmann, F. Justus Liebigs Ann. Chem. 1904, 332, 38-81. doi:10.1002/jlac.19043320104

16. Ullmann, F.; Bielecki, J. Ber. Dtsch. Chem. Ges. 1901, 34, 2174-2185. doi:10.1002/cber.190103402141

17. Xu, J.; Wang, X.; Shao, C.; Su, D.; Cheng, G.; Hu, Y. Org. Lett. 2010, 12, 1964-1967. doi:10.1021/ol1003884

18. Chen, S.; Jia, L.; Li, X.; Luo, M. Synthesis 2014, 263-268. doi:10.1055/s-0033-1340285

19. Guo, S.; Lu, L.; Cai, H. Synlett 2013, 1712-1714. doi:10.1055/s-0033-1339303

20. Gogoi, A.; Bora, U. Synlett 2012, 1079-1081. doi:10.1055/s-0031-1290654

21. Anderson, K. W.; Ikawa, T.; Tundel, R. E.; Buchwald, S. L. J. Am. Chem. Soc. 2006, 128, 10694-10695. doi:10.1021/ja0639719

22. Chen, G.; Chan, A. S. C.; Kwong, F. Y. Tetrahedron Lett. 2007, 48, 473-476. doi:10.1016/j.tetlet.2006.11.036

23. Schulz, T.; Torborg, C.; Schäffner, B.; Huang, J.; Zapf, A.; Kadyrov, R.; Börner, A.; Beller, M. Angew. Chem., Int. Ed. 2009, 48, 918-921. doi:10.1002/anie.200804898

24. Sergeev, A. G.; Schulz, T.; Torborg, C.; Spannenberg, A.; Neumann, H.; Beller, M. Angew. Chem., Int. Ed. 2009, 48, 7595-7599. doi:10.1002/anie.200902148

25. Gallon, B. J.; Kojima, R. W.; Kaner, R. B.; Diaconescu, P. L. Angew. Chem., Int. Ed. 2007, 46, 7251-7254. doi:10.1002/anie.200701389

26. Havasi, F.; Ghorbani-Choghamarani, A.; Nikpoura, F. New J. Chem. 2015, 39, 6504-6512. doi:10.1039/C5NJ01102G

27. Tlili, A.; Xia, N.; Monnier, F.; Taillefer, M. Angew. Chem., Int. Ed. 2009, 48, 8725-8728. doi:10.1002/anie.200903639

28. Taillefer, M.; Monnier, F.; Tlili, A.; Xia, N. Method for the Hydroxylation of Halogenated Aryl Compounds. WO Patent WO2010142913, Dec 16, 2010.

29. Lefèvre, G.; Franc, G.; Tlili, A.; Adamo, C.; Taillefer, M.; Ciofini, I.; Jutand, A. Organometallics 2012, 31, 7694-7707. doi:10.1021/om300636f

30. Zhao, D.; Wu, N.; Zhang, S.; Xi, P.; Su, X.; Lan, J.; You, J. Angew. Chem., Int. Ed. 2009, 48, 8729-8732. doi:10.1002/anie.200903923

31. Jia, J.; Jiang, C.; Zhang, X.; Jiang, Y.; Ma, D. Tetrahedron Lett. 2011, 52, 5593-5595. doi:10.1016/j.tetlet.2011.08.059

32. Mehmood, A.; Leadbeater, N. E. Catal. Commun. 2010, 12, 64-66. doi:10.1016/j.catcom.2010.07.011

33. Yang, D.; Fu, H. Chem. - Eur. J. 2010, 16, 2366-2370. doi:10.1002/chem.200903468

34. Thakur, K. G.; Sekar, G. Chem. Commun. 2011, 47, 6692-6694. doi:10.1039/c1cc10782h

35. Amal Joseph, P. J.; Priyadarshini, S.; Lakshmi Kantam, M.; Maheswaran, H. Catal. Sci. Technol. 2011, 1, 582-585. doi:10.1039/c0cy00090f

36. Chen, J.; Yuan, T.; Hao, W.; Cai, M. Catal. Commun. 2011, 12, 1463-1465. doi:10.1016/j.catcom.2011.06.002 
37. Xiao, Y.; Xu, Y.; Cheon, H.-S.; Chae, J. J. Org. Chem. 2013, 78, 5804-5809. doi:10.1021/j0400702z

38. Song, G.-L.; Zhang, Z.; Da, Y.-X.; Wang, X.-C. Tetrahedron 2015, 71, 8823-8829. doi:10.1016/j.tet.2015.08.066

39. Liu, Y.; Park, S. K.; Xiao, Y.; Chae, J. Org. Biomol. Chem. 2014, 12, 4747-4753. doi:10.1039/c4ob00649f

40. Kim, J.; Battsengel, O.; Liu, Y.; Chae, J. Bull. Korean Chem. Soc. 2015, 36, 2833-2840. doi:10.1002/bkcs.10576

41. Paul, R.; Ali, Md. A.; Punniyamurthy, T. Synthesis 2010, 4268-4272. doi:10.1055/s-0030-1258965

42. Maurer, S.; Liu, W.; Zhang, X.; Jiang, Y.; Ma, D. Synlett 2010, 976-978. doi:10.1055/s-0029-1219548

43. Yang, K.; Li, Z.; Wang, Z.; Yao, Z.; Jiang, S. Org. Lett. 2011, 13, 4340-4343. doi:10.1021/ol2016737

44. Jing, L.; Wei, J.; Zhou, L.; Huang, Z.; Li, Z.; Zhou, X. Chem. Commun. 2010, 46, 4767-4769. doi:10.1039/c0cc00434k

45. Ke, F.; Chen, X.; Li, Z.; Xiang, H.; Zhou, X. RSC Adv. 2013, 3, 22837-22840. doi:10.1039/c3ra44613a

46. Wang, D.; Kuang, D.; Zhang, F.; Tang, S.; Jiang, W. Eur. J. Org. Chem. 2014, 315-318. doi:10.1002/ejoc.201301370

47. Xu, H.-J.; Liang, Y.-F.; Cai, Z.-Y.; Qi, H.-X.; Yang, C.-Y.; Feng, Y.-S. J. Org. Chem. 2011, 76, 2296-2300. doi:10.1021/jo102506x

48. Ding, G.; Han, H.; Jiang, T.; Wu, T.; Han, B. Chem. Commun. 2014, 50, 9072-9075. doi:10.1039/C4CC02267J

49. Jintoku, T.; Nishimura, K.; Takaki, K.; Fujiwara, Y. Chem. Lett. 1990, 19, 1687-1688. doi:10.1246/cl.1990.1687

50. Jintoku, T.; Nishimura, K.; Takaki, K.; Fujiwara, Y. Chem. Lett. 1991, 20, 193-194. doi:10.1246/cl.1991.193

51. Seo, Y.-J.; Mukai, Y.; Tagawa, T.; Goto, S. J. Mol. Catal. A: Chem. 1997, 120, 149-154. doi:10.1016/S1381-1169(96)00426-8

52. Taktak, S.; Flook, M.; Foxman, B. M.; Que, L., Jr.; Rybak-Akimova, E. V. Chem. Commun. 2005, 5301-5303. doi:10.1039/b508004e

53. Chen, X.; Hao, X.-S.; Goodhue, C. E.; Yu, J.-Q. J. Am. Chem. Soc. 2006, 128, 6790-6791. doi:10.1021/ja061715q

54. Krylov, I. B.; Vil', V. A.; Terent'ev, A. O. Beilstein J. Org. Chem. 2015, 11, 92-146. doi:10.3762/bjoc.11.13

55. Li, X.; Liu, Y.-H.; Gu, W.-J.; Li, B.; Chen, F.-J.; Shi, B.-F. Org. Lett. 2014, 16, 3904-3907. doi:10.1021/ol5016064

56. Singh, B. K.; Jana, R. J. Org. Chem. 2016, 81, 831-841. doi:10.1021/acs.joc.5b02302

57. Liu, Q.; Wu, P.; Yang, Y.; Zeng, Z.; Liu, J.; Yi, H.; Lei, A. Angew. Chem., Int. Ed. 2012, 51, 4666-4670. doi:10.1002/anie.201200750

58. Wang, D.; Yu, X.; Yao, W.; Hu, W.; Ge, C.; Shi, X. Chem. - Eur. J. 2016, 22, 5543-5546. doi:10.1002/chem.201600597

59. Kim, S. H.; Lee, H. S.; Kim, S. H.; Kim, J. N. Tetrahedron Lett. 2008, 49, 5863-5866. doi:10.1016/j.tetlet.2008.07.141

60. Yan, Y.; Feng, P.; Zheng, Q.-Z.; Liang, Y.-F.; Lu, J.-F.; Cui, Y.; Jiao, N. Angew. Chem., Int. Ed. 2013, 52, 5827-5831. doi:10.1002/anie.201300957

61. Yamaguchi, T.; Yamaguchi, E.; Tada, N.; Itoh, A. Adv. Synth. Catal. 2015, 357, 2017-2021. doi:10.1002/adsc.201500061

62. Dong, J.; Liu, P.; Sun, P. J. Org. Chem. 2015, 80, 2925-2929. doi:10.1021/acs.joc.5b00167

63. Das, P.; Saha, D.; Saha, D.; Guin, J. ACS Catal. 2016, 6, 6050-6054. doi:10.1021/acscatal.6b01539

64. Banerjee, A.; Bera, A.; Guin, S.; Rout, S. K.; Patel, B. K. Tetrahedron 2013, 69, 2175-2183. doi:10.1016/j.tet.2012.12.067
65. Kamal, A.; Srinivasulu, V.; Sathish, M.; Tangella, Y.; Nayak, V. L.; Rao, M. P. N.; Shankaraiah, N.; Nagesh, N. Asian J. Org. Chem. 2014, 3, 68-76. doi:10.1002/ajoc.201300214

66. Seth, K.; Nautiyal, M.; Purohit, P.; Parikh, N.; Chakraborti, A. K. Chem. Commun. 2015, 51, 191-194. doi:10.1039/C4CC06864E

67. Liang, Y.-F.; Wang, X.; Yuan, Y.; Liang, Y.; Li, X.; Jiao, N. ACS Catal. 2015, 5, 6148-6152. doi:10.1021/acscatal.5b01700

68. Maji, A.; Bhaskararao, B.; Singha, S.; Sunoj, R. B.; Maiti, D. Chem. Sci. 2016, 7, 3147-3153. doi:10.1039/C5SC04060D

69. Zhang, Y.-H.; Yu, J.-Q. J. Am. Chem. Soc. 2009, 131, 14654-14655. doi:10.1021/ja907198n

70. Shan, G.; Yang, X.; Ma, L.; Rao, Y. Angew. Chem., Int. Ed. 2012, 51, 13070-13074. doi:10.1002/anie.201207458

71. Mo, F.; Trzepkowski, L. J.; Dong, G. Angew. Chem., Int. Ed. 2012, 51, 13075-13079. doi:10.1002/anie.201207479

72. Choy, P. Y.; Kwong, F. Y. Org. Lett. 2013, 15, 270-273. doi:10.1021/ol303088z

73. Zhang, H.-Y.; Yi, H.-M.; Wang, G.-W.; Yang, B.; Yang, S.-D. Org. Lett. 2013, 15, 6186-6189. doi:10.1021/ol403028a

74. Duan, S.; Xu, Y.; Zhang, X.; Fan, X. Chem. Commun. 2016, 52, 10529-10532. doi:10.1039/C6CC04756D

75. Thirunavukkarasu, V. S.; Hubrich, J.; Ackermann, L. Org. Lett. 2012, 14, 4210-4213. doi:10.1021/ol3018819

76. Thirunavukkarasu, S. V.; Ackermann, L. Org. Lett. 2012, 14, 6206-6209. doi:10.1021/ol302956s

77. Liu, W.; Ackermann, L. Org. Lett. 2013, 15, 3484-3486. doi:10.1021/ol401535k

78. Yang, F.; Rauch, K.; Kettelhoit, K.; Ackermann, L. Angew. Chem., Int. Ed. 2014, 53, 11285-11288. doi:10.1002/anie.201405647

79. Yang, Y.; Lin, Y.; Rao, Y. Org. Lett. 2012, 14, 2874-2877. doi:10.1021/ol301104n

80. Yang, X.; Shan, G.; Rao, Y. Org. Lett. 2013, 15, 2334-2337. doi:10.1021/ol400437a

81. Yang, X.; Sun, Y.; Chen, Z.; Rao, Y. Adv. Synth. Catal. 2014, 356, 1625-1630. doi:10.1002/adsc.201300999

82. Sun, Y.-H.; Sun, T.-Y.; Wu, Y.-D.; Zhang, X.; Rao, Y. Chem. Sci. 2016, 7, 2229-2238. doi:10.1039/C5SC03905C

83. Kim, K.; Choe, H.; Jeong, Y.; Lee, J. H.; Hong, S. Org. Lett. 2015, 17, 2550-2553. doi:10.1021/acs.orglett.5b01138

84. Kamata, K.; Yamaura, T.; Mizuno, N. Angew. Chem., Int. Ed. 2012, 51, 7275-7278. doi:10.1002/anie.201201605

85. Li, Y.; Li, B.; Geng, L.; Wang, J.; Wang, Y.; Huang, J. Catal. Lett. 2015, 145, 1014-1021. doi:10.1007/s10562-015-1478-7

86. Leuckart, R. J. Prakt. Chem. 1890, 41, 179-224. doi:10.1002/prac.18900410114

87. Newman, M. S.; Karne, H. A. J. Org. Chem. 1966, 31, 3980-3984. doi:10.1021/jo01350a023

88. Kwart, H.; Evans, E. R. J. Org. Chem. 1966, 31, 410-413. doi:10.1021/jo01340a015

89. Schönberg, A.; v. Vargha, L. Chem. Ber. 1930, 63, 178-180. doi:10.1002/cber.19300630125

90. Testaferri, L.; Tingoli, M.; Tiecco, M. Tetrahedron Lett. 1980, 21, 3099-3100. doi:10.1016/S0040-4039(00)77418-1

91. Testaferri, L.; Tiecco, M.; Tingoli, M.; Chianelli, D.; Montanucci, M. Synthesis 1983, 751-755. doi:10.1055/s-1983-30501

92. Shaw, J. E. J. Org. Chem. 1991, 56, 3728-3729. doi:10.1021/jo00011a057

93. Nasri, N. S.; Jones, J. M.; Dupont, V. A.; Williams, A. Energy Fuels 1998, 12, 1130-1134. doi:10.1021/ef980104j 
94. Rodriguez, J. A.; Hrbek, J. Acc. Chem. Res. 1999, 32, 719-728. doi:10.1021/ar9801191

95. Sun, L.-L.; Deng, C.-L.; Tang, R.-Y.; Zhang, X.-G. J. Org. Chem 2011, 76, 7546-7550. doi:10.1021/jo201081v

96. Kuhn, M.; Falk, F. C.; Paradies, J. Org. Lett. 2011, 13, 4100-4103. doi:10.1021/ol2016093

97. Tiecco, M.; Tingoli, M. J. Org. Chem. 1985, 50, 3828-3831. doi:10.1021/jo00220a029

98. Qiao, S.; Xie, K.; Qi, J. Chin. J. Chem. 2010, 28, 1441-1443. doi:10.1002/cjoc.201090246

99. Itoh, T.; Mase, T. Org. Lett. 2004, 6, 4587-4590. doi:10.1021/ol047996t

100.Fernández-Rodríguez, M. A.; Hartwig, J. F. Chem. - Eur. J. 2010, 16, 2355-2359. doi:10.1002/chem.200902313

101.Yi, J.; Fu, Y.; Xiao, B.; Cui, W.-C.; Guo, Q.-X. Tetrahedron Lett. 2011, 52, 205-208. doi:10.1016/j.tetlet.2010.10.128

102.Sawada, N.; Itoh, T.; Yasuda, N. Tetrahedron Lett. 2006, 47, 6595-6597. doi:10.1016/j.tetlet.2006.07.008

103.Jiang, Y.; Qin, Y.; Xie, S.; Zhang, X.; Dong, J.; Ma, D. Org. Lett. 2009, 11, 5250-5253. doi:10.1021/ol902186d

104.Palani, T.; Park, K.; Song, K. H.; Lee, S. Adv. Synth. Catal. 2013, 355, 1160-1168. doi:10.1002/adsc.201201106

105.Liu, Y.; Kim, J.; Seo, H.; Park, S.; Chae, J. Adv. Synth. Catal. 2015, 357, 2205-2212. doi:10.1002/adsc.201400941

\section{License and Terms}

This is an Open Access article under the terms of the Creative Commons Attribution License (http://creativecommons.org/licenses/by/4.0), which permits unrestricted use, distribution, and reproduction in any medium, provided the original work is properly cited.

The license is subject to the Beilstein Journal of Organic Chemistry terms and conditions:

(http://www.beilstein-journals.org/bjoc)

The definitive version of this article is the electronic one which can be found at: doi:10.3762/bjoc. 13.58 